\title{
Central-West Argentina Summer Precipitation Variability and Atmospheric Teleconnections
}

\author{
Eduardo A. Agosta \\ Consejo Nacional de Investigaciones Científicas y Técnicas, and Equipo Interdisciplinario para el Estudio de Procesos \\ Atmosféricos en el Cambio Global, Pontificia Universidad Católica Argentina, Buenos Aires, Argentina \\ Rosa H. COMPAGNUCCI \\ Consejo Nacional de Investigaciones Científicas y Técnicas, and Departamento de Ciencias de la Atmósfera y los Océanos, \\ Universidad de Buenos Aires, Buenos Aires, Argentina
}

(Manuscript received 6 April 2011, in final form 23 August 2011)

\begin{abstract}
The interannual-to-multidecadal variability of central-west Argentina (CWA) summer (October-March) precipitation and associated tropospheric circulation are studied in the period 1900-2010. Precipitation shows significant quasi cycles with periods of about 2, 4-5, 6-8, and 16-22 yr. The quasi-bidecadal oscillation is significant from the early 1910s until the mid-1970s and is present in pressure time series over the southwestern South Atlantic. According to the lower-frequency spectral variation, a prolonged wet spell is observed from 1973 to the early 2000s. The precipitation variability shows a reversal trend since then. In that wet epoch, the regionally averaged precipitation has been increased about $24 \%$. The lower-frequency spectral variation is attributed to the climate shift of 1976/77.

From the early twentieth century until the mid-1970s, the precipitation variability is associated with barotropic quasi-stationary wave (QSW) propagation from the tropical southern Indian Ocean and the South Pacific, generating vertical motion and moisture anomalies at middle-to-subtropical latitudes east of the Andes over southern South America. The QSW propagation could be related to anomalous convection partly induced by tropical anomalous SSTs in the western Indian Ocean (WIO). It could also be linked to another midlatitude source along the storm tracks, to the east of New Zealand.

After 1976/77, the precipitation variability is associated with equatorial symmetric circulation anomalies linked to El Niño-Southern Oscillation (ENSO)-like warmer conditions. Positive moisture anomalies are consistently observed at lower latitudes in association with inflation of the western flank of the South Atlantic anticyclone. Outside of this, the precipitation variability is unrelated to ENSO.
\end{abstract}

\section{Introduction}

Since the late nineteenth century, the central-west Argentina (CWA; Fig. 1) region has developed an economy based on grape production that highly depends on climate fluctuations, especially on precipitation during the warm season (Agosta and Cavagnaro 2010). Hence, summer rainfall variability and its extremes are of great concern because of their important economic impacts with deep cultural implications. The region is located to the east of the southern Andean mountain ranges in

Corresponding author address: Eduardo Andres Agosta, PEPACG, Pontificia Universidad Católica Argentina., Av. Alicia Moreau de Justo 1600, 3er piso, Buenos Aires C1455AVC, Argentina.

E-mail: eduardo.agosta@conicet.gov.ar southern South America. The subtropical southern Andes have a mean elevation of about $4500 \mathrm{~m}$, being a natural barrier for humidity advection from the midlatitude South Pacific by westerlies (Schwerdtfeger 1976). Hence, its climate is classified as being desert to semidesert, from west to east (Hoffmann 1992). The warm season (from October to March) accounts for more than $85 \%$ on average of the regional annual rainfall, showing a sharp annual cycle (Agosta and Compagnucci 2006). The summer mean lowlevel atmospheric circulation is influenced by northeasterly flow of the subtropical quasi-stationary South Atlantic anticyclone (SAA), the continental tropical "Chaco" low, and the westerlies farther southward (Schwerdtfeger 1976; Agosta and Compagnucci 2008, hereafter AC08).

Compagnucci et al. (2002) studied the interannual variability of CWA summer rainfalls in the period 1900-98 


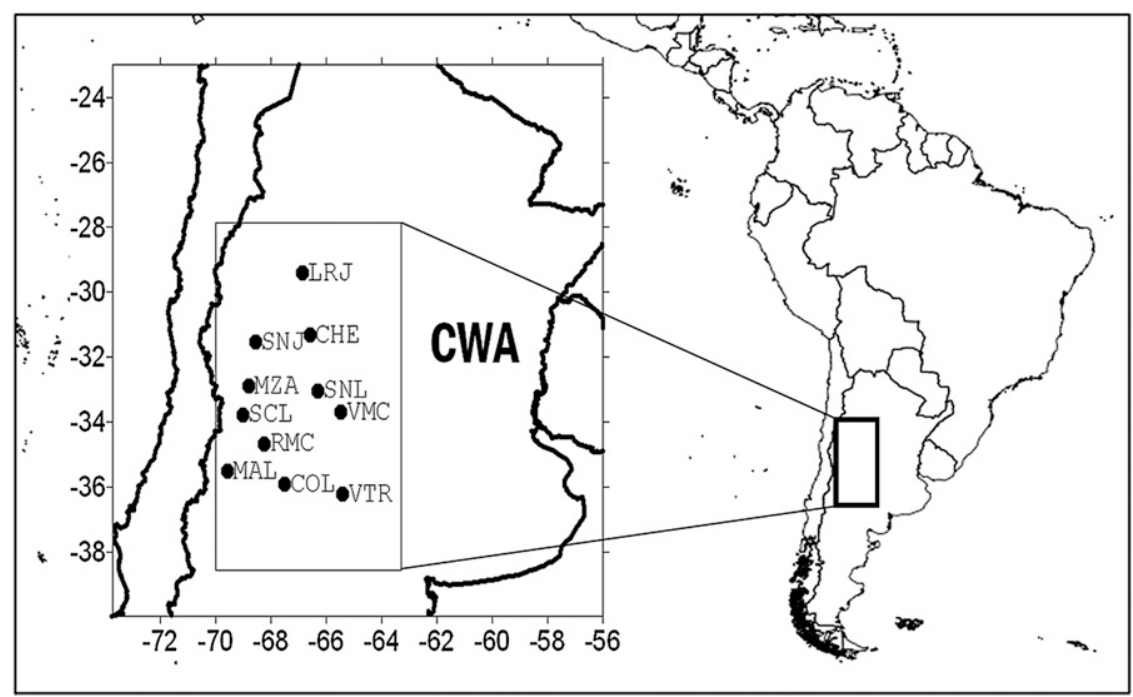

FIG. 1. Map of location of the meteorological stations within the CWA region $\left(29^{\circ}-36^{\circ} \mathrm{S}\right.$, $\left.65^{\circ}-70^{\circ} \mathrm{W}\right)$. For station names see Table 1.

using filtering functions and Fourier spectral analysis. They found significant spectral peaks in the low frequencies. The quasi oscillation near $18 \mathrm{yr}$ is noticeable since it is active until the mid-1970s, showing wet and dry alternating spells of about $9 \mathrm{yr}$ each. However, since that date the quasibidecadal oscillation has decayed, leading to a prolonged wet spell that lasted, at least, until 1998. The authors argued that the widely documented 1976/77 climate shift, associated with anomalous warming in the central Pacific (Ebbesmeyer et al. 1991; Mantua et al. 1997; Solomon et al. 2007; Barreiro 2010), could have modified the atmospheric circulation over South America, affecting precipitation variability.

In addition the CWA summer precipitation variability is remotely in phase, related to the summer rainfall region (SRR) precipitation variability in South Africa (Tyson et al. 1975) that also exhibits a quasi-18-yr cycle (Compagnucci et al. 2002; Tyson 1986). The teleconnection between both regions disappeared after the mid-1970s (Compagnucci et al. 2002) since the SRR has not undergone changes in its low-frequency variability (Mason 1996; Lizcano and Todd 2005).

Recently, AC08 examined the impacts of the 1976/77 climate shift on the summer synoptic-scale tropospheric circulation over southern South America using principal component analysis applied on National Centers for Environmental Prediction-National Center for Atmospheric Research (NCEP-NCAR) reanalysis daily geopotential height fields. After the summer of 1976/77, we found a westward expansion of the SAA over subtropical-totropical South America and lower midlatitude cyclonic activity. The synoptic-scale tropospheric circulation changes produced a net enhanced northerly flow, transporting higher humid air masses from lower latitudes toward subtropical Argentina. The authors found that the change can account for increases in precipitation and water budget that were observed in subtropical southern South American regions (Barros et al. 1996, 2000; Robertson and Mechoso 1998; Rusticucci and Penalba 2000; Piovano et al. 2004). In this sense, Renom et al. (2011) have also found significant changes in extreme temperature events in Uruguay, southeastern South America, that are related to the climate transition of 1976/77.

In consequence, this study aims to examine the CWA interannual-to-multidecadal summer precipitation variability and its connection with Southern Hemisphere ( $\mathrm{SH}$ ) tropospheric circulation variations. Special emphasis is given to possible seasonal atmospheric teleconnection changes due to the climate shift of $1976 / 77$, as suggested by previous studies.

\section{Data and methodology}

\section{a. Station precipitation data and empirical summer rainfall index}

Regional precipitation data consist of monthly rainfall from 10 meteorological stations, located in CWA (see Table 1), from the Servicio Meteorológico Nacional (Argentine Weather Service). The information is used to estimate the regional summer precipitation (SR) index, as it was formerly devised by Agosta et al. (1999) and used by Compagnucci et al. (2002). The index SR is estimated like the standardized total summer rainfall at each station, averaged across all the stations. Since the austral warm 
TABLE 1. Meteorological stations that are used for the construction of the SR index in the CWA region (at approximately $28^{\circ}-37^{\circ} \mathrm{S}$, $65^{\circ}-70^{\circ} \mathrm{W}$; see also Fig. 1 ).

\begin{tabular}{lcccl}
\hline $\begin{array}{c}\text { Station } \\
\text { name }\end{array}$ & $\begin{array}{c}\text { Height } \\
(\mathrm{m})\end{array}$ & $\begin{array}{c}\text { Latitude } \\
\left({ }^{\circ} \mathrm{S}\right)\end{array}$ & $\begin{array}{c}\text { Longitude } \\
\left({ }^{\circ} \mathrm{W}\right)\end{array}$ & Record \\
\hline LRJ & 516 & 29.42 & 66.87 & $1904-2010$ \\
SNJ & 634 & 31.32 & 68.57 & $1900-2010$ \\
CHE & 658 & 31.33 & 66.60 & $1930-90$ \\
MZA & 769 & 32.88 & 68.82 & $1900-2010$ \\
SNL & 734 & 33.03 & 66.32 & $1905-2010$ \\
VMC & 514 & 33.68 & 65.48 & $1900-2010$ \\
SCR & 940 & 33.77 & 69.01 & $1938-79$ \\
RMC & 713 & 34.67 & 68.40 & $1927-2010$ \\
COL & 465 & 35.00 & 67.69 & $1935-79$ \\
MAL & 1425 & 35.50 & 69.58 & $1953-2010$ \\
VTR & 312 & 36.23 & 65.43 & $1905-2010$ \\
\hline
\end{tabular}

season starts in October of one year and ends in March of the following year, the "summer year" is indicated as the year corresponding to March. For example, the season from October 1959 to March 1960 will be the summer of 1960. The baseline used for standardization is 1961-90 for which positive (negative) values of SR denote above (below) regional-average summers. Hence, the SR index time series captures the interannual-tomultidecadal variability of summer rainfalls in CWA (Compagnucci et al. 2002).

\section{b. Gridded precipitation, atmospheric and oceanic data}

To examine the relationship between the CWA precipitation and the regional precipitation field over southern South America, monthly $0.5^{\circ}$ latitude-longitude interpolated rainfall data, version 2 (1901-2008), from the University of Delaware (UD) are used. The UD gridded rainfall data are available at the Climate Diagnostics Center Web site (CDC, http://www.esrl.noaa.gov/psd/ data/gridded/data.UDel_AirT_Precip.html). Noticeably, the UD gridded summer precipitation time series, averaged on the area corresponding to CWA, presents a strong correlation with the SR index of 0.92 for the period 1901-2008, significant at $99 \%$. This is indicative of the good representativeness of the UD precipitation data for the spatial-temporal scales used for study.

Information about atmospheric variables is obtained using $2.5^{\circ}$ latitude-longitude gridded monthly data from the National Centers for Environmental PredictionNational Center for Atmospheric Research (NCEPNCAR) Reanalysis I, available from the CDC. The variables are geopotential height $(\mathrm{GH}$, gpm), vector wind ( $U$ and $V$, zonal and meridional components, respectively; $\mathrm{m} \mathrm{s}^{-1}$ ), specific humidity (shum, $\mathrm{g} \mathrm{kg}^{-1}$ ), and vertical velocity (omega, $\mathrm{Pa} \mathrm{s}^{-1}$ ). Streamfunction (PSI in $\mathrm{m}^{2} \mathrm{~s}^{-1}$ ) and velocity potential (CHI in $\mathrm{m}^{2} \mathrm{~s}^{-1}$ ) fields are derived from UV fields using a Poisson solver FORTRAN code (Swarztrauber and Sweet 1975). Most of the reanalysis variables are available at 17 standardized levels, but shum and omega are available at 8 and 10 levels, respectively. Reanalysis-derived outgoing longwave radiation (OLR, watts $\mathrm{m}^{-2}$ ) is also used for analysis of convection in the tropics.

Additionally, reconstructed sea level pressure (SLP) monthly anomalies on a global $5^{\circ}$ latitude-longitude grid are provided by the Hadley Centre. They are available in two versions: the first Hadley Centre Sea Level Pressure dataset (HadSLP1) (1871-1998) and the second HadSLP (HadSLP2) (1850-2010). The Met Office Web page on datasets (http://hadobs.metoffice.com/gmslp/) suggests considering the HadSLP2 dataset as a preference. However, the comparison between both databases, with the NCEP-NCAR reanalysis for the common period and specifically with the SLP station data at Stanley $\left(51.70^{\circ} \mathrm{S}\right.$, $57.85^{\circ} \mathrm{W}$ ), indicate that HadSLP1 is the best for this analysis (see the appendix).

Extended reconstructed monthly sea surface temperature (SST) version 3 data are provided by the National Oceanic and Atmospheric Administration (www.esrl. noaa.gov/psd/data/gridded/data.noaa.ersst.html) on a global $2^{\circ}$ latitude-longitude grid from 1854 to the present. Oceanic indices such as the global SST El Niño-Southern Oscillation (ENSO) index (EN) and the multivariate ENSO index (MEI) are available online at http://jisao. washington.edu/data_sets/globalsstenso/ and http://www. esrl.noaa.gov/psd/enso/mei/, respectively, and are used herein.

\section{c. Time series analysis and composite anomalies}

Time series are analyzed in section 3 using simple trend detection techniques, such as the construction of the cumulative seasonal anomaly time series and the 30-yr climatologies time series (L with the "Morlet" wavelet as mother function, is used to decompose time series into time-frequency space to isolate different modes of variability and to examine how they vary in time (wavelet power spectrum). Edge effects are reduced by padding with zeros. Further details on wavelet analysis can be found in Torrence and Compo (1998).

Tropospheric circulations anomalies related to wet and dry summer conditions observed in CWA are analyzed by means of composite anomaly fields. Composite fields are constructed according to low and high SR index values, given by the first and third quartiles from the detrended SR index frequency distribution. Summers with detrended SR values below the first quartile $\left(Q_{1}=\right.$ $-0.54)$ are considered dry condition summer and values above the third quartile $\left(Q_{3}=+0.53\right)$, wet condition summer. The classified summer years using this criterion 
TABLE 2 . Wet and dry summers according to the quartile criterion for the high and low SR index distribution. First quartile, Q1 = -0.54 ; third quartile, Q3 $=+0.53$.

\begin{tabular}{cc}
\hline \hline Wet summers & $1904,1919,1920,1921,1922,1923,1925,1926$, \\
$($ SR $>$ Q3) & $1927,1940,1941,1944,1945,1956,1957$, \\
& $1960,1963,1973,1974,1977,1978,1979$, \\
& $1984,1985,1998,2000,2007,2008$ \\
Dry summers & $1903,1909,1913,1917,1930,1934,1936,1937$, \\
$($ SR $<$ Q1) & $1938,1939,1942,1948,1949,1950,1951$, \\
& $1955,1966,1967,1969,1971,1972,1976$, \\
& $1989,1994,1996,2004,2006,2010$ \\
\hline
\end{tabular}

are displayed in Table 2 for the season period 1901-10. In a first step (sections 4 and 5), tropospheric anomalies are studied using the NCEP-NCAR reanalysis data after the summer of 1959. Although reanalysis monthly data are available since 1948, the considered period is more confident for analysis in the SH (Kistler et al. 2001).

Atmospheric circulation anomalies relative to the climate shift of 1976/77 are analyzed, dividing the summer climatology period into 1959-76 and 1979-2010. This further allows us to diminish potential inhomogeneities due to the incorporation of satellite information in the reanalysis (Kistler et al. 2001). In a second step (section 6), tropospheric anomalies are studied for the whole past century, adding information provided by the HadSLP reconstructions.

Teleconnections are studied by zonal asymmetries of the PSI wet-minus-dry composite difference field, thus obtaining anomalous eddies (Karoly et al. 1989), which can likewise be quasi-stationary waves (QSWs) if there is wave propagation under certain assumptions. Hence, QSW energy propagation is analyzed using the conservative horizontal components of the wave activity flux developed by Plumb (1985). The wave activity flux is parallel to the velocity group, and its divergence (convergence) can be related to wave activity source (sink).

Composite anomalies are tested using unequal variance Student's $t$ test (Moser and Stevens 1992), for levels $\alpha$ at 0.05 and 0.10 . The unequal $t$ test is a stronger test than the conventional $t$ test under statistical changes in sampled variances. Conventional Pearson's first moment single and 30-yr running correlations are estimated for different time series.

\section{Low-frequency variability in the CWA summer rainfall}

The CWA summer rainfall index (SR) time series is shown in Fig. 2a. The overall behavior shows a significant positive trend (correlation of 0.26 , significant at $\alpha=0.05$ ) and relevant interannual variability. Since only the stationary component of low-frequency processes within the instrumental period are to be analyzed in this section, the linearly detrended SR time series will be considered for further analysis. Besides, the denoted smoothed time series emphasizes the existence of interdecadal quasi oscillations with periods over $15 \mathrm{yr}$.

Furthermore, the existence of long-term oscillations is revealed by the $30-\mathrm{yr}$ climatologies time series and the cumulative seasonal time series derived from the detrended SR time series (Fig. 2b). Both time series show an oscillation with a period of about $45 \mathrm{yr}$ together with other embedded shorter fluctuations. The quasi-45-yr period oscillation presents extreme phases in approximately the summers of 1927 and 1972 for both series. A concavity variation in the cumulative seasonal time series highlights trend changes on its derivative that is the detrended SR index time series. Hence, the somewhat longterm trend changes occur in 1917, 1927, 1972, and about 1985. Other minor trend changes can also be identified (in about 1906, 1939, 1946, 1955, and 1966), and both major and minor trend changes are directly linked to the phase changes induced by low-frequency oscillations, as those evidenced by the $15-\mathrm{yr}$ smoothed SR time series (Fig. 2a). It is noteworthy that after the mid-1980s, the cumulative seasonal time series shows oscillations of about 6-8 yr.

The 30-yr climatologies time series indicate that the driest 30-yr long-term interval in the century expands between 1928 and 1957, whereas the wettest 30-yr long-term interval expands between 1973 and 2002. After 1970, the lowest 30-yr climatology value is recorded in 1981, which means that the 1981-2010 epoch shows a precipitation average lower than 10 previous 30 -yr periods. Hence, the last 3 decades of the twentieth century are evidently the wettest, and it appears that the extended wet interval is gradually ending from the early 2000s onward.

A wavelet analysis on the detrended SR time series objectively captures lower-frequency variations and gives further details for the above-mentioned findings. The CWT power spectrum is shown in Fig. 3. Significant oscillations with a period of about 16-22 yr start in about 1910 and finish by the early 1970s. Afterward, this quasi-bidecadal oscillation loses significance, presenting decreasing CWT power values until the end of the record. Shorter quasioscillations are significant with periods about $2 \mathrm{yr}$ in the late 1990s, 4-5 yr in the 1920s and the 1940s, $6 \mathrm{yr}$ in the 1970s, and 8 yr in the 1990s. Generally, the periodicities are in accordance with those found previously by Compagnucci et al. (2002).

There is no doubt that an extended wet spell has started by the early 1970s, characterized by shorter intradecadal quasi-oscillations. More precisely, the wet interval seems to have started with the summer of 1973 as a natural part of the former quasi-bidecadal oscillation. The relative frequency of wet summers between the subperiods before 


\section{a)}

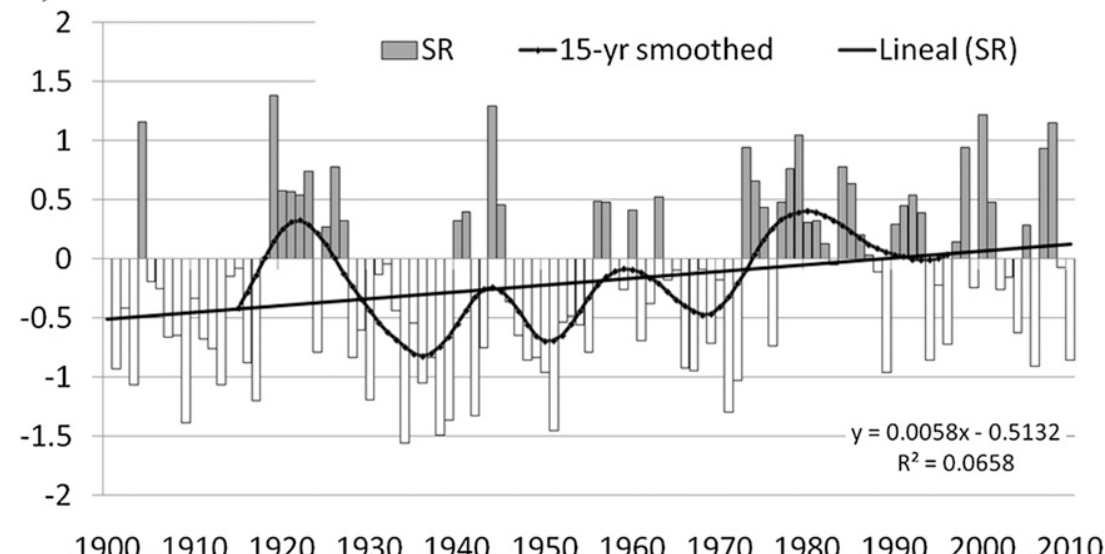

b)

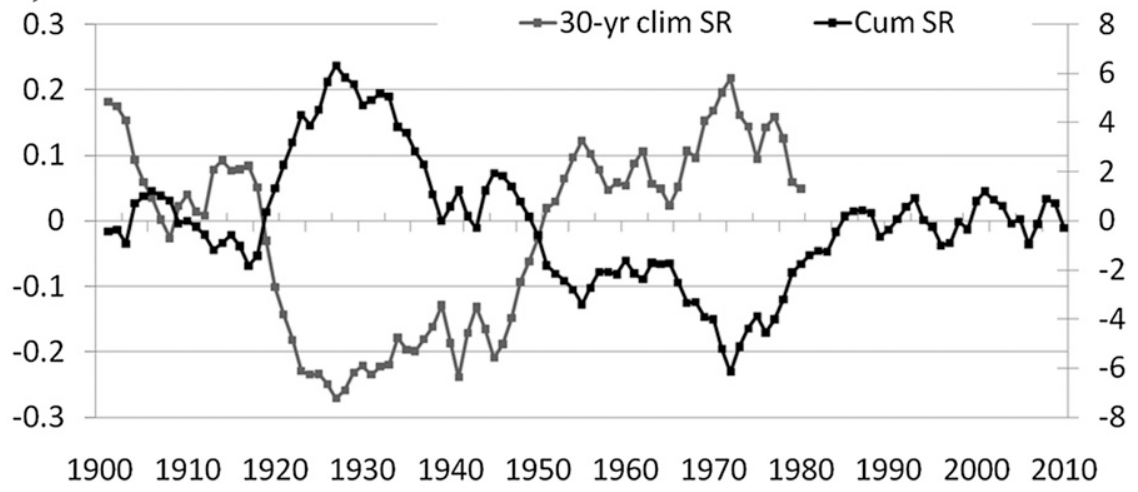

FIG. 2. (a) The CWA SR index time series, devised using meteorological station data (vertical bars); the 15-yr smoothed SR index time series (15-yr smoothed) and the linear trend for SR time series (lineal SR). Linear trend equation is at the bottom-right corner, and the explained variance is $R^{2}$. (b) The 30-yr climatologies SR time series (30-yr clim SR, in gray) and the cumulative SR time series (Cum SR, in black).

and after 1973 has slightly increased from $23.6 \%$ to $29 \%$, whereas the relative frequency of dry summers has been quite reduced since then from $29.2 \%$ to $18.4 \%$. Hence, a consequent increase in the regionally averaged rainfall of about $24 \%$ is observed in the last 4 decades, being significant at $95 \%$ (Student's $t$ test).

The extension in time of the last wet spell, which according to the former quasi-bidecadal oscillation should
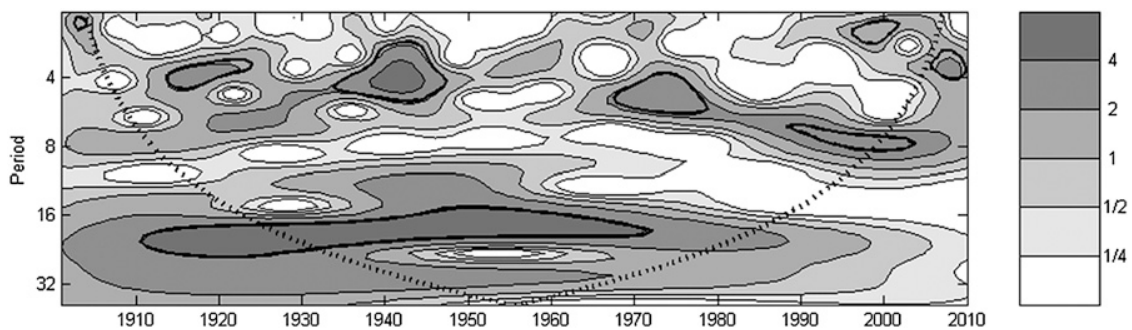

FIG. 3. The local wavelet power spectrum of the SR index for CWA summer rainfalls using the Morlet wavelet. The left axis is the Fourier period (yr). The bottom axis is time (yr). Solid thick contour encloses $95 \%$ of confidence for a red-noise process with a lag- 1 coefficient of 0.43 . Shaded contours are explained variances at $4=50 \%, 2=25 \%, 1=12.5 \%, 1 / 2=6.25 \%$, and $1 / 4=3.125 \%$. Dotted line: cone of influence; values between the line and the borders of the graph have important edge effects. 
have ended by the early 1980 s, can be ascribed to the 1976/77 climate shift affecting CWA summer rainfalls (Compagnucci et al. 2002). Recently, AC08 found that as a consequence of this climate shift, the southern South American summer low-level tropospheric circulation has undergone a reduction in the midlatitude cyclonic activity and westward expansion of SAA at synoptic scale. The authors suggested that these circulation variations have significant impact on the precipitation budget in subtropical Argentina (north of $40^{\circ} \mathrm{S}$ ), even on the CWA rainfall variability. Positive trends in precipitation during the warm season over most of eastern subtropical Argentina, corresponding to the wet "pampas" region in which annual precipitation is prominent (more than $800 \mathrm{~mm}$ ), are also observed after 1970 and can be associated with the SAA circulation variability (Barros et al. 2008).

In summary, the climate shift of 1976/77 has affected the CWA rainfall variability. This fact is evidenced by the decaying quasi-bidecadal oscillation and the generation of shorter low-frequency oscillations, both observed after the mid-1970s. As a consequence, the longest wet interval in the last century started in 1973 and lasted until, at least, the early 2000s, significantly increasing regional summer rainfalls in CWA during the last 4 decades. The 1976/77 climate shift is an atmosphere-ocean couple process modifying teleconnection patterns which in turn affect different regions of the globe (Namias 1978; Ebbesmeyer et al. 1991; Dettinger et al. 2001). It is worthy to determine which seasonal teleconnections changes could have modified the CWA rainfalls variability, if possible.

\section{Continental tropospheric circulation anomalies and the CWA rainfall using NCEP-NCAR reanalysis}

In this section seasonal tropospheric circulation anomalies will be inspected before and after the summer climate shift of 1976/77 to determine those changes associated with wet and dry conditions in CWA. The composite anomalies within each period are constructed with the NCEP-NCAR reanalysis I data, and they are further compared with UD precipitation composite fields to evaluate the extension of the precipitation signal.

\section{a. Anomalies in the summer period 1959-76}

The 850- and 300-hPa GH composite anomalies for the wet summers (Figs. 4a and $4 \mathrm{~b}$ ) are contrasted with those for dry summers (Figs. $4 \mathrm{c}$ and $4 \mathrm{~d}$ ). The shading indicates significant areas at $\alpha=0.10$ (light gray) and $\alpha=0.05$ (gray). The outstanding anomalies are close to the southern tip of South America, showing mirror-like anomalies between wet and dry composites. Anticyclonic (cyclonic) significant anomalies are centered at about $50^{\circ} \mathrm{S}-55^{\circ} \mathrm{W}$, zonally extending from the continent tip to the southwestern South Atlantic for the wet (dry) composite. The GH anomaly centers tilt slightly westward from lower troposphere (Figs. 4a and 4b) to upper troposphere (Figs. $4 \mathrm{c}$ and $4 \mathrm{~d}$ ), indicating an equivalent barotropic nature. Opposite-sign anomalies are observed in the subtropical South Atlantic for both wet and dry composites, suggesting anomalous wave patterns. The presence of these midlatitude seasonal GH anomalies suggests low-frequency modulations of the westerlies related to the midlatitude cyclonic-anticyclonic activity variations.

The mirrored behaviors that present the anomalies allow us to examine the wet-minus-dry anomalous composite difference for other atmospheric variables. The composite difference anomalies of UV and shum at $850 \mathrm{hPa}$ and of omega at $500 \mathrm{hPa}$ are shown in Figs. 5a and 5b, respectively. Low-level shum anomalies are accordingly high (low) over western lands of Argentina, to the east of the Andes for wet (dry) summer conditions in CWA. The highest absolute values of more than $0.6 \mathrm{~g} \mathrm{~kg}^{-1}$ fall well within the CWA region, extending significantly farther southeast toward northern Patagonia.

The direct positive shum anomalies are associated with the anomalous southeasterly wind components (Fig. 5a) induced by the anticyclonic anomalies (Fig. 4a). The perturbation in the circulation brings anomalous moisture from the southwest South Atlantic (south of $30^{\circ} \mathrm{S}$ ) toward CWA and lower latitudes. The opposite situation describes dryer conditions with vector wind anomalies induced by cyclonic anomalies (Fig. 4b) from the south-southwest near CWA. This anomalous circulation, due to the Andes natural barrier, inhibits moisture transport from the South Pacific. In addition, in the middle troposphere, negative (positive) upward motion omega anomalies of about $-0.015 \mathrm{~Pa} \mathrm{~s}^{-1}$ appear to be significant over CWA, suggesting anomalous upper-level dynamic conditions favorable for wet (dry) conditions (Fig. 5b). The UD precipitation difference composite field confirms the moisture spatial distribution induced by the tropospheric circulation perturbation (Fig. 6a). The resulting precipitation anomalies suggest a dipole in the sign of precipitation anomalies between the subtropical latitudes to the east of the Andes and the tropical latitudes in eastern-southern South America.

\section{b. Anomalies in the summer period 1979-2010}

The 850- and 300-hPa GH anomalies for the wet summers (Figs. 4e and 4f) and dry summers (Figs. 4g and 4h) show a different configuration from the previous period, being a distinctive mirror pattern.

During wet conditions the tropospheric $\mathrm{GH}$ anomalies (Figs. 4e and 4f), although not significant, present similar high-latitude anomalies extending from the lower to 

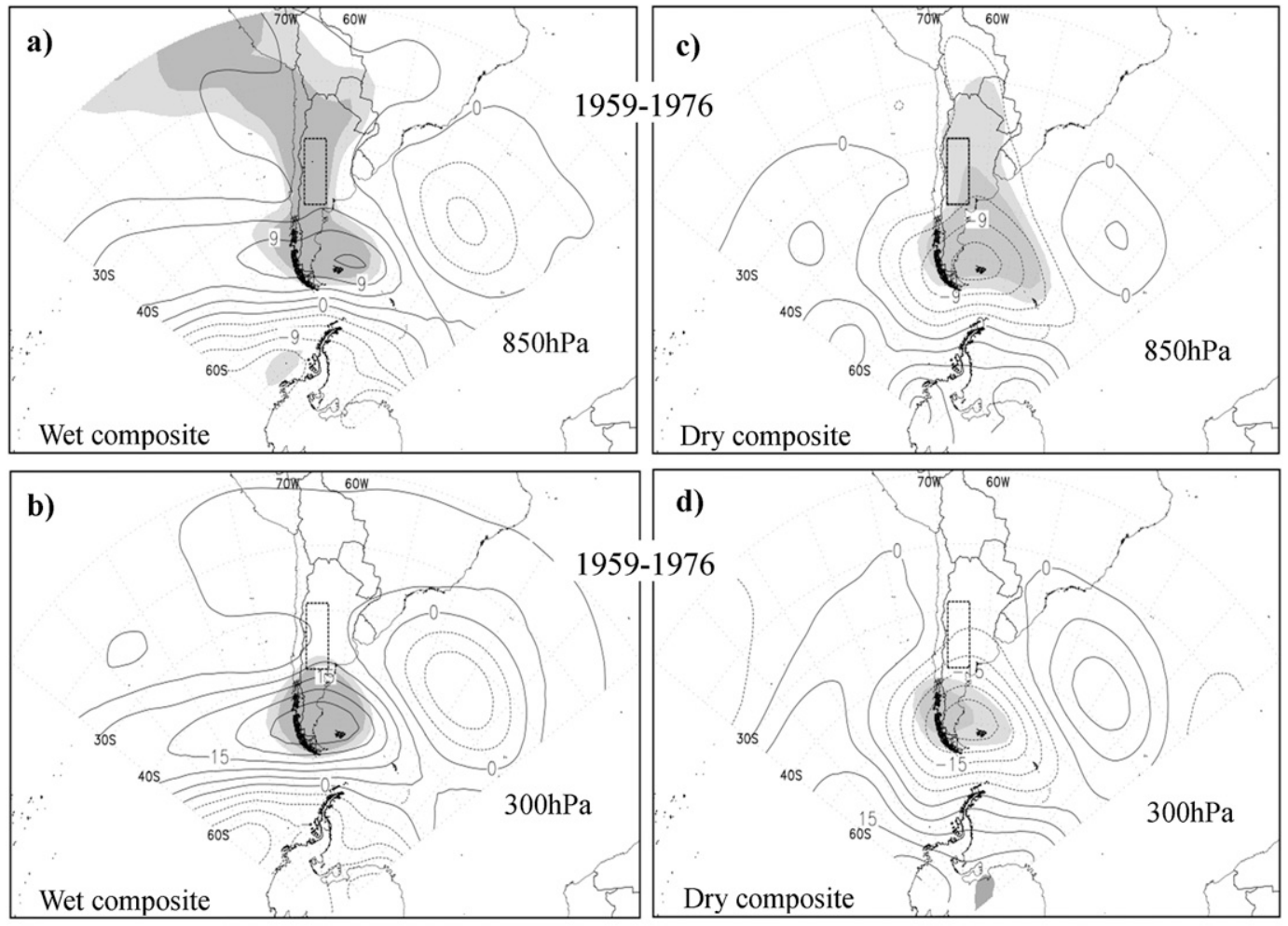

d)
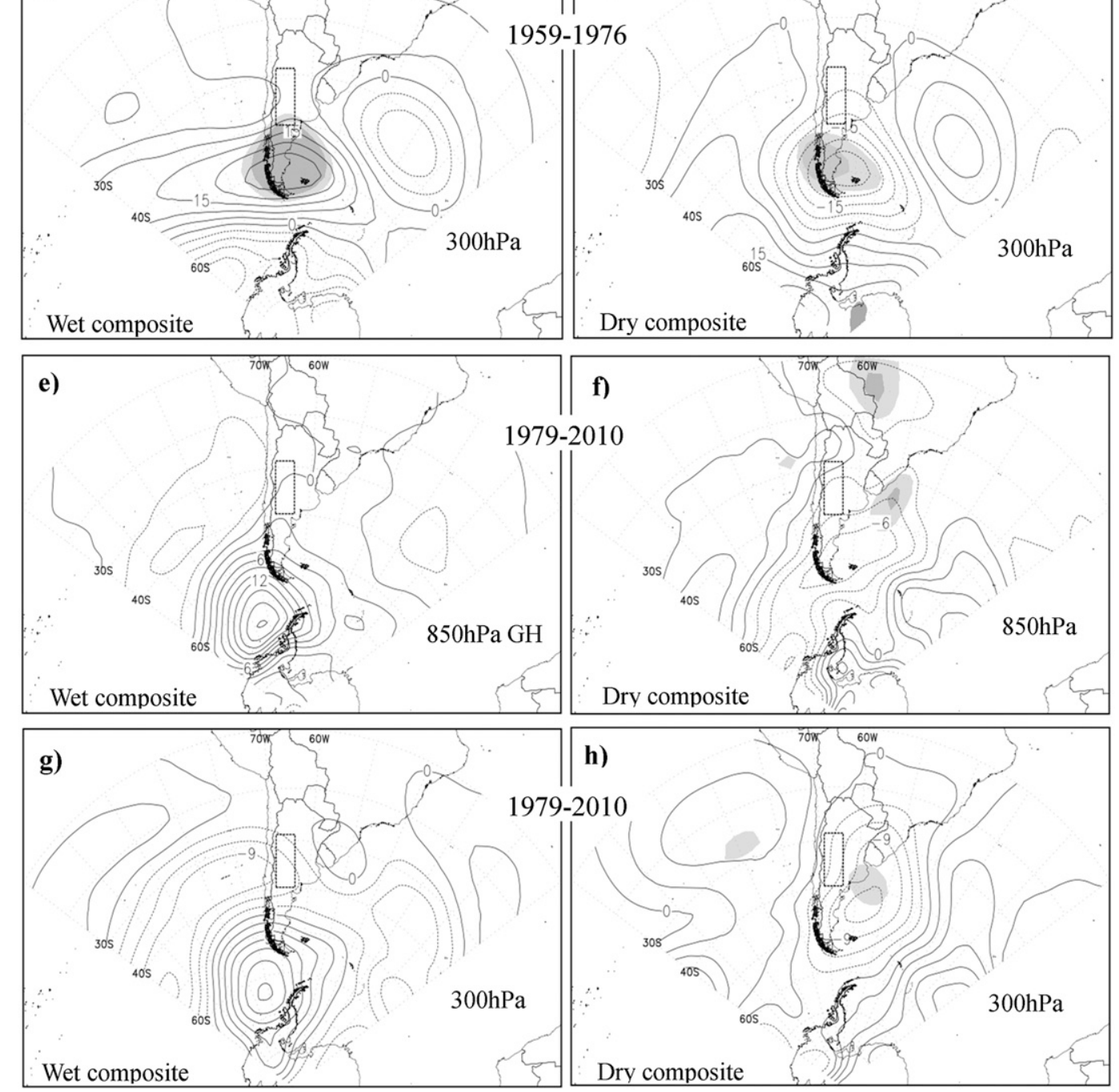

FIG. 4. The GH composite anomalies (gpm) for (left) wet summers composite and (right) dry summers composite in the periods (a)-(d) 1959-76 and (e)-(h) 1979-2010, according to the first and third quartile criterion for SR index (years used for each composite are listed in Table 2), at (a),(c),(e),(f) 850 and (b),(c),(g),(h) $300 \mathrm{hPa}$. Shaded areas are significant anomalies at the $90 \%$ (lighter gray) and $95 \%$ (gray) confidence levels using the unequal variance Student's $t$ test. 
1959-1976
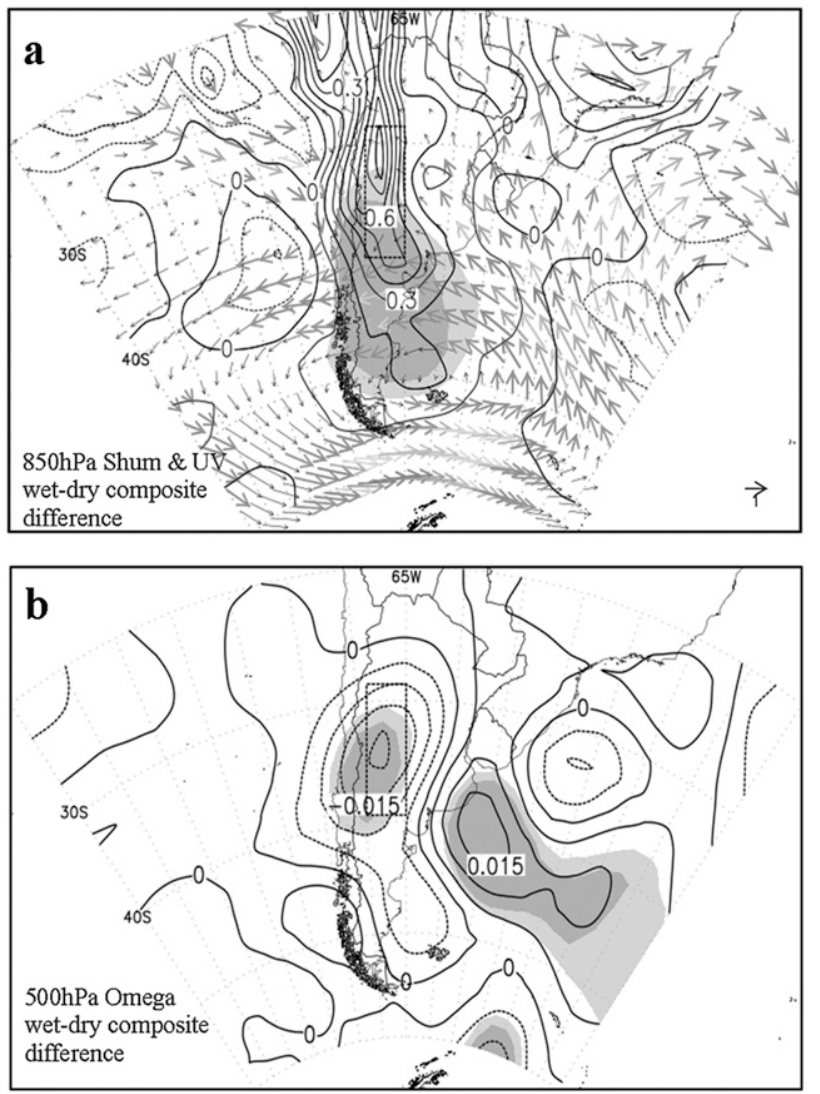

1979-2010
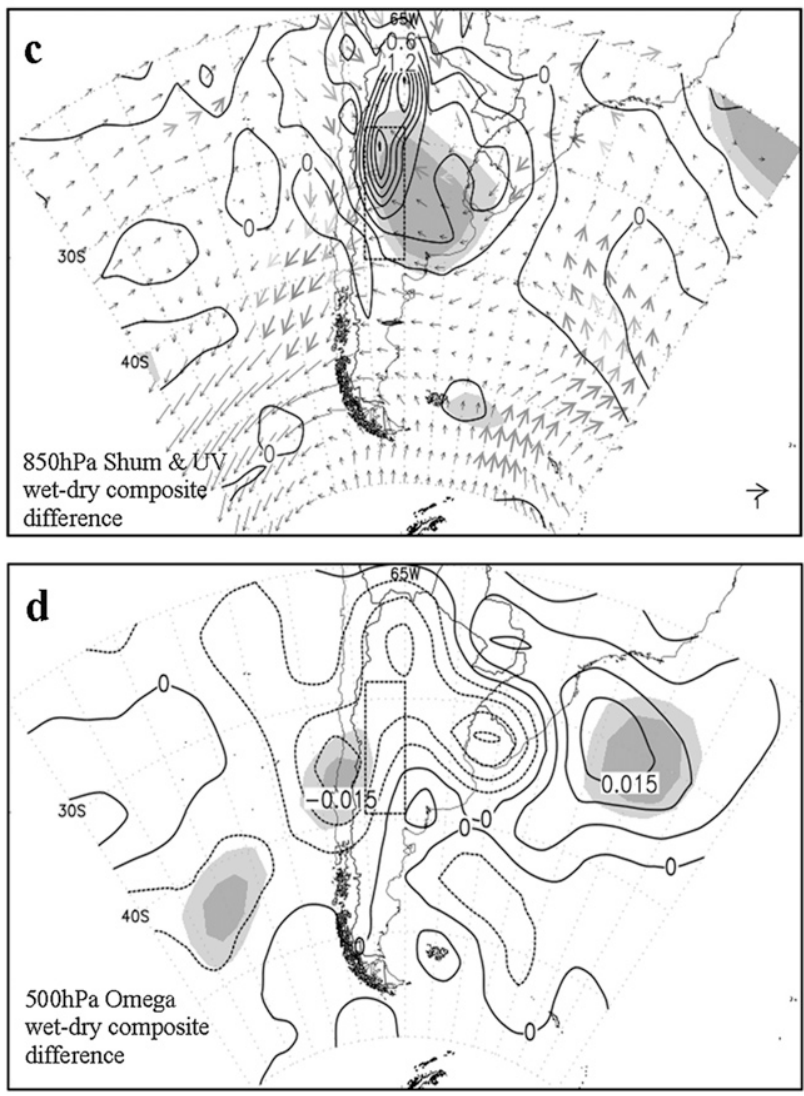

FIG. 5. (a),(b) The 850-hPa shum (g kg ${ }^{-1}$, thick contour) and UV (vectors, $\mathrm{m} \mathrm{s}^{-1}$ ), and (b),(d) 500-hPa omega (1 Pa $\left.{ }^{-1}\right)$. Wet-minus-dry composite difference anomalies for the periods (a),(b) 1959-76 and (c),(d) 1979-2010. Shaded areas are significant shum and omega anomalies at the $90 \%$ (lighter gray) and 95\% (gray) confidence levels using the unequal variance Student's $t$ test. Highlighted vectors are significant above the $90 \%$ confidence level.

upper troposphere over the southwest off South America. The overall GH anomalies pattern establishes a negative quasi-meridional pressure gradient between the subtropical South Pacific area and higher latitudes. The lack of significance in the anomalies reveals the presence of higher variability within the set of wet summers for the composite during this period.

During dry conditions (Figs. $4 \mathrm{~g}$ and $4 \mathrm{~h}$ ) the anomalies hardly mirror the wet condition anomalies, only the reversal of the quasi-meridional pressure gradient from the subtropical Pacific to higher latitudes. Significant cyclonic anomalies are present in the southwest sector of the South Atlantic off the coast and at tropical latitudes on the continent. The negative GH anomalies, far off the coast, seem to be similar to the anomalies for dry condition that were observed in the years prior to 1977 (cf. with Figs. 4c and 4d).

The wet-minus-dry composite difference anomalies for 850-hPa shum and UV and 500-hPa omega are shown in Figs. $5 \mathrm{c}$ and 5d, respectively. During wet summers positive low-level shum anomalies with values of more than
$0.6 \mathrm{~g} \mathrm{~kg}^{-1}$ are observed over central-northwest Argentina with respect to dry summers. The area corresponding to CWA is inside the positive anomalies, though the strongest anomalies are placed northward. In comparison with dry summers, the 850-hPa UV anomalies show an anomalous cyclonic circulation over continental subtropical latitudes during wet summers, providing positive anomalous moisture from lower latitudes and the South Atlantic (Fig. 5c).

The 500-hPa omega difference anomaly shows relative upward motion conditions during wet summers with respect to dry summers over continental subtropical latitudes (Fig. 5d). The UD precipitation difference anomalies also show larger and positive anomalies at most of the east and lower latitudes, suggesting a change in the source of moisture advection (Fig. 6b) in comparison with the previous period (Fig. 6a).

The individual wet and dry composite fields show anomalies of vector winds, vertical motion, and specific humidity that are congruent with the previous wet-minus-dry composite patterns (figures not shown). 

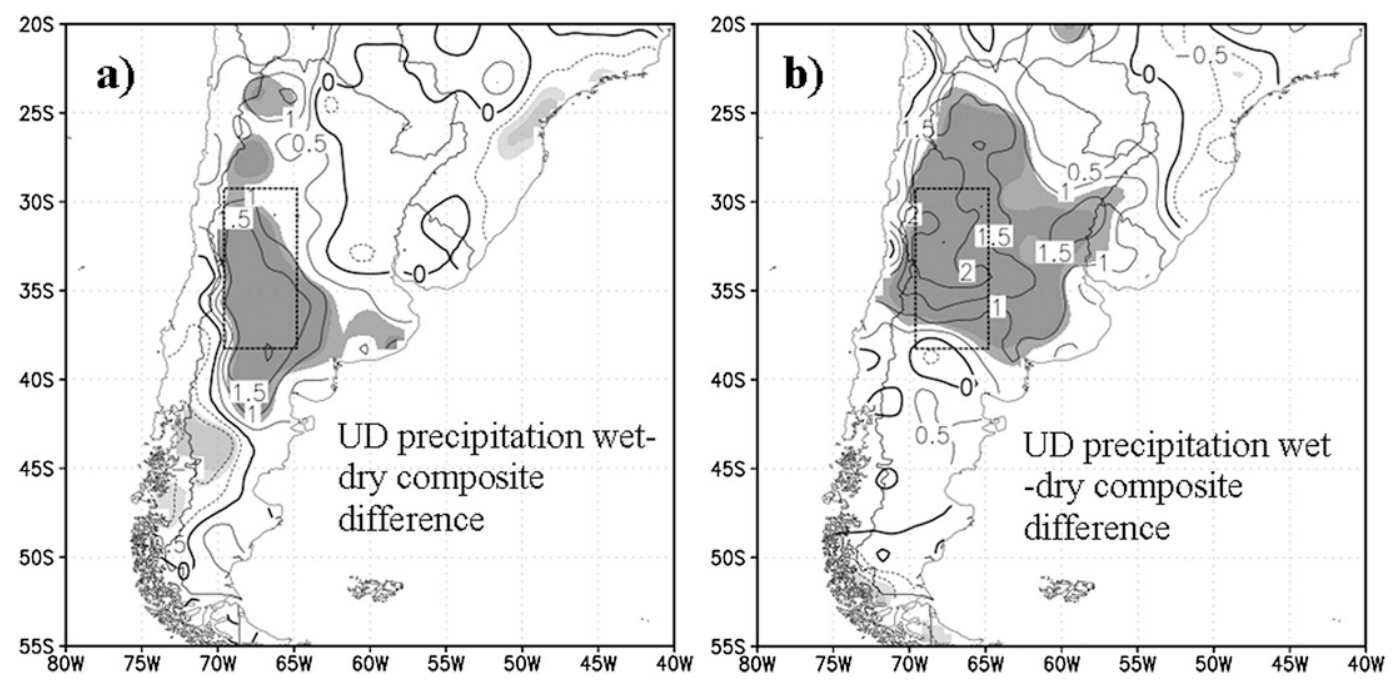

FIG. 6. Gridded UD precipitation wet-minus-dry summers composite difference anomalies during (a) 1959-76 and (b) 1978-2010, expressed as standard deviation anomalies for the period 1961-90 (thick contours every 0.5 std devs). Shaded areas are significant anomalies at the 90\% (lighter gray) and 95\% (gray) confidence levels using the unequal variance Student's $t$ test.

\section{c. Tropospheric anomalies' dissimilarity before and after 1976/77}

According to AC08, the summer low-level circulation over South America presents significant inhomogeneities at subtropical and midlatitudes before and after 1976/77, as a consequence of the 1976/77 climate shift. Since the climatological backgrounds are different in each subperiod, they should be filtered out to analyze the difference between both wet and dry summer composites for before and after the 1976/77 climate shift. Hence, the filtered wet (dry) composite difference field is estimated as the difference between the wet (dry) summer composite difference (i.e., the summer composite for 1979-2010 minus the one for 1959-1976) and the climatological anomalies between the subperiods. Their statistical significance is tested using the inhomogeneity test between two subsamples, adopted from Yamamoto et al. (1986).

The filtered wet composite difference for both $\mathrm{GH}$ and $\mathrm{UV}$ anomalies at 850 and $300 \mathrm{hPa}$ are shown in Fig. 7. The lower- and upper-level GH anomalies show enhancement of the SAA western flank, inducing easterly and northeasterly anomalous vector winds toward continental subtropical latitudes for the wet summer after 1977 (Figs. 7a and 7b). Even though GH anomalies are not significant, the UV wind anomalies in the western flank of the SAA are significant at $\alpha=0.10$. Midlatitude cyclonic GH anomalies, extending throughout the troposphere, further induce anomalous upper-level northerly winds (Fig. 7b). These cyclonic anomalies are indicative that the midlatitude anticyclonic perturbation, responsible for moisture advection during wet summers from the southern South Atlantic south of $30^{\circ} \mathrm{S}$ in the period before 1977 (see Fig. 4a), could be less prominent after 1977 .

Moreover, the low-level shum wet composite difference field, for which anomalies are vertically integrated from 925 to $700 \mathrm{hPa}$ (Fig. 7c), shows positive moisture anomalies over continental subtropical latitudes. In consequence, the wet summers present higher moisture content after 1977, in part as a consequence of anomalous warmer tropical airmass advection by the SAA (Figs. 7a and $7 \mathrm{~b}$ ). Despite the absence of statistical significance, these shum anomalies are congruent with the general pattern of increased precipitation within subtropical Argentina that has been observed since the 1970s (Barros et al. 2008), especially in the CWA region (Agosta and Compagnucci 2006; AC08). Besides, wet-minus-wet composite difference anomalies for the UD precipitation show some significant areas of positive anomalies over CWA that extend toward eastern subtropical Argentina (Fig. 7d). This gives further consistency to the above-mentioned circulation and moisture anomalies. For the period prior to 1977 , the shum anomalies are overall negative in subtropical latitudes in accordance with a reduced SAA activity in comparison to the period after 1977. Since filtered composites for dry summers mirror the wet ones, they are not shown.

In summary after 1976/77, summer moisture anomalies in CWA are linked to tropospheric circulation anomalies associated with the SAA western flank, which affects subtropical Argentina to the north of $40^{\circ} \mathrm{S}$. This is in accordance with AC08's findings at synoptic scale. The 

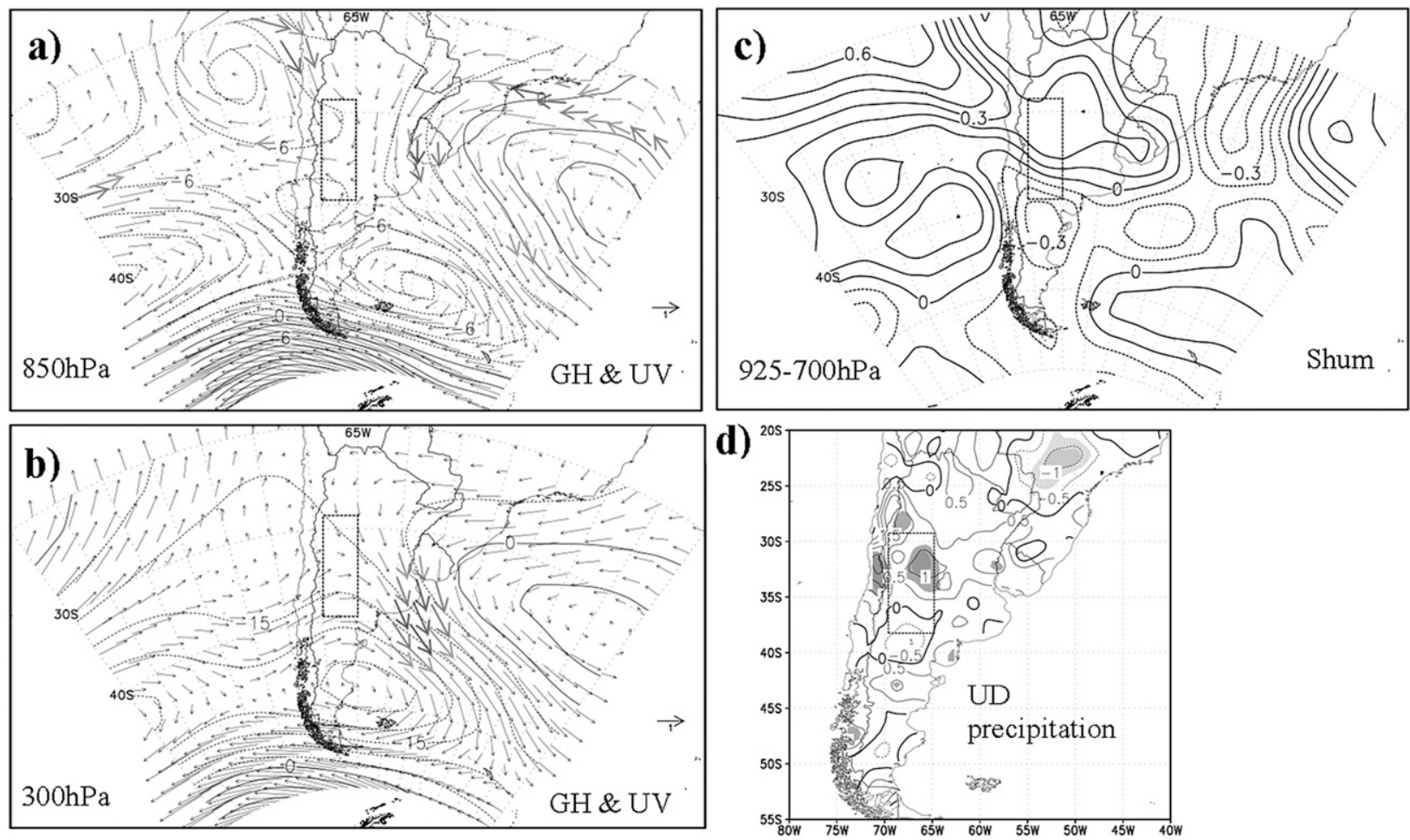

FIG. 7. Filtered wet minus wet-composite difference anomalies (for the definition, see text) for GH (in gpm) and UV ( $\mathrm{m} \mathrm{s}^{-1}$ ) at (a) 850 and (b) $300 \mathrm{hPa}$, for (c) 925-700-hPa-integrated shum, and (d) UD precipitation (in std dev units). Highlighted vectors are significant above the $90 \%$ confidence level. Shaded areas in (d) are significant at the $90 \%$ (lighter gray) and 95\% (gray) confidence levels.

strengthening of the SAA could be related to upper-level mass convergence in relation to anomalous warming in the central Pacific because of the 1976/77 climate shift (Nogués-Paegle et al. 2002; AC08).

\section{Tropospheric teleconnection patterns and the CWA rainfall variability}

In this section teleconnection patterns are identified by estimating the high-minus-low index composite difference of atmospheric variables, which yields similar results to correlation or regression maps (Karoly et al. 1989).

\section{a. Teleconnections in the period from 1959 to 1976}

The 300- and 850-hPa PSI anomalous eddies, together with the associated QSW activity flux (Plumb 1985), are shown in Figs. 8a and 8b, respectively. Prior to the climate shift of 1976/77, anomalous eddies extend from tropical to midlatitudes in the Indian Ocean toward the south and east. The zonally asymmetric PSI anomalies extend farther over the midlatitude South Pacific toward South America. All of them present equivalent barotropic vertical structure. The horizontal Plumb's wave activity flux denote QSW-activity propagation from the midlatitude Indian Ocean eastward to the South Pacific, followed by a second wave propagation from the New Zealand sector in the South Pacific toward South America. There seems to be another source of stationary wave in tropical and subtropical latitudes to the northwest of Australia propagating to the southeast; however, the validity of the Plumb's wave activity flux at lower latitudes is suspect because of quasigeostrophic assumptions made in its derivation (Plumb 1985). In the extratropics an active source of Rossby wave propagation is the anomalous divergent winds in the presence of strong mean vorticity gradients, as those associated with the subtropical jets at about $30^{\circ} \mathrm{S}$ over the Indian Ocean and the South Pacific (Sardeshmukh and Hoskins 1988). This mechanism is independent from the position of the tropical heating. The potential velocity composite anomalies in fact shows anomalous southward divergent winds in the subtropics, at about $30^{\circ} \mathrm{S}, 100^{\circ} \mathrm{E}$, over the midlatitude Indian Ocean (figures not shown), which could be linked to the emanation of wave energy.

The corresponding OLR composite difference anomalies are shown in Fig. 8c. Negative OLR anomalies are extended over most of the tropical Indian Ocean toward the midlatitude South Pacific (crossing over Australia and New Zealand), being indicative of anomalous convection there. The significant OLR anomalies in the eastern 
a)

$300 \mathrm{hPa}$ PSI eddy \& Fs
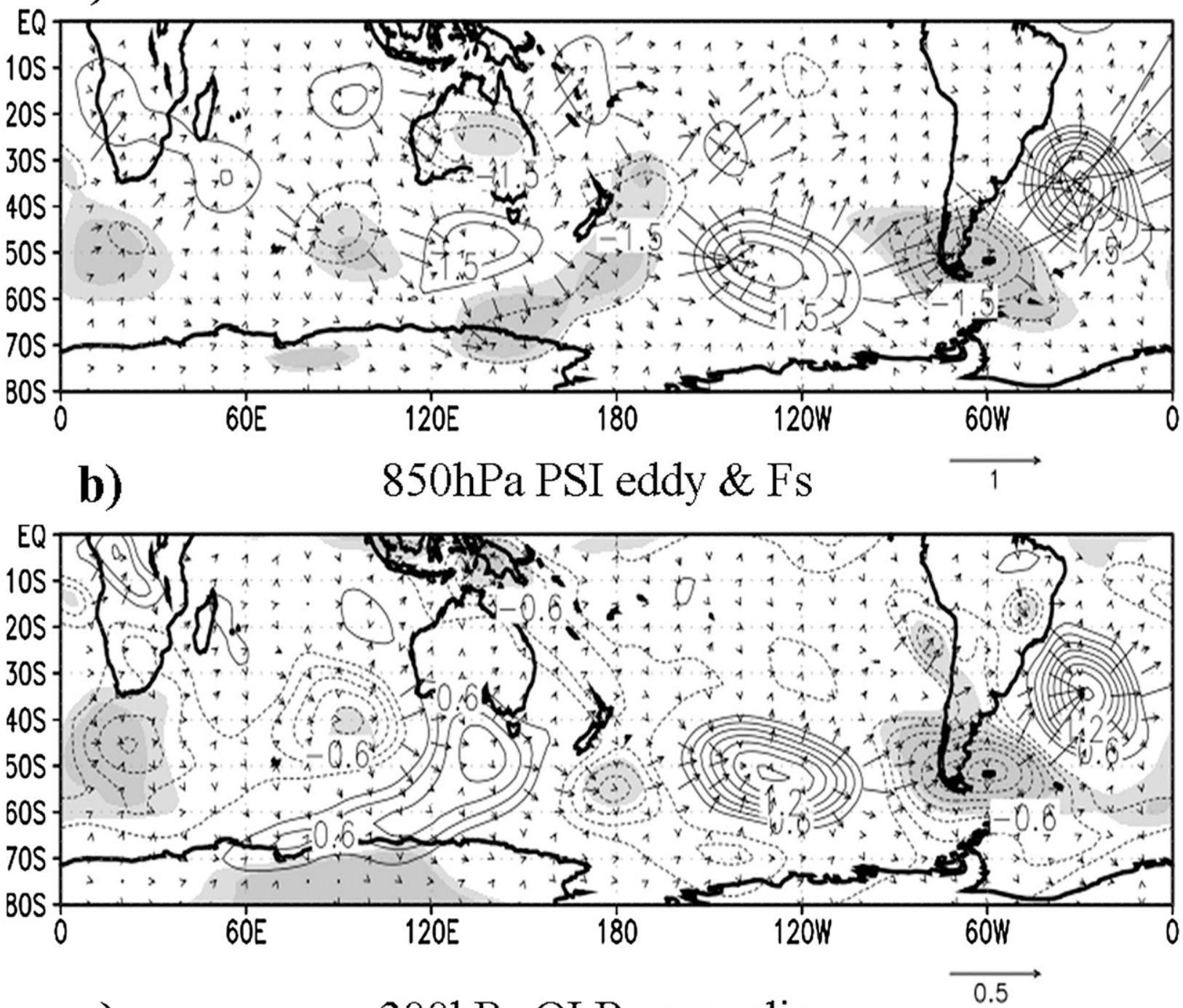

c) $\quad 300 \mathrm{hPa}$ OLR anomalies

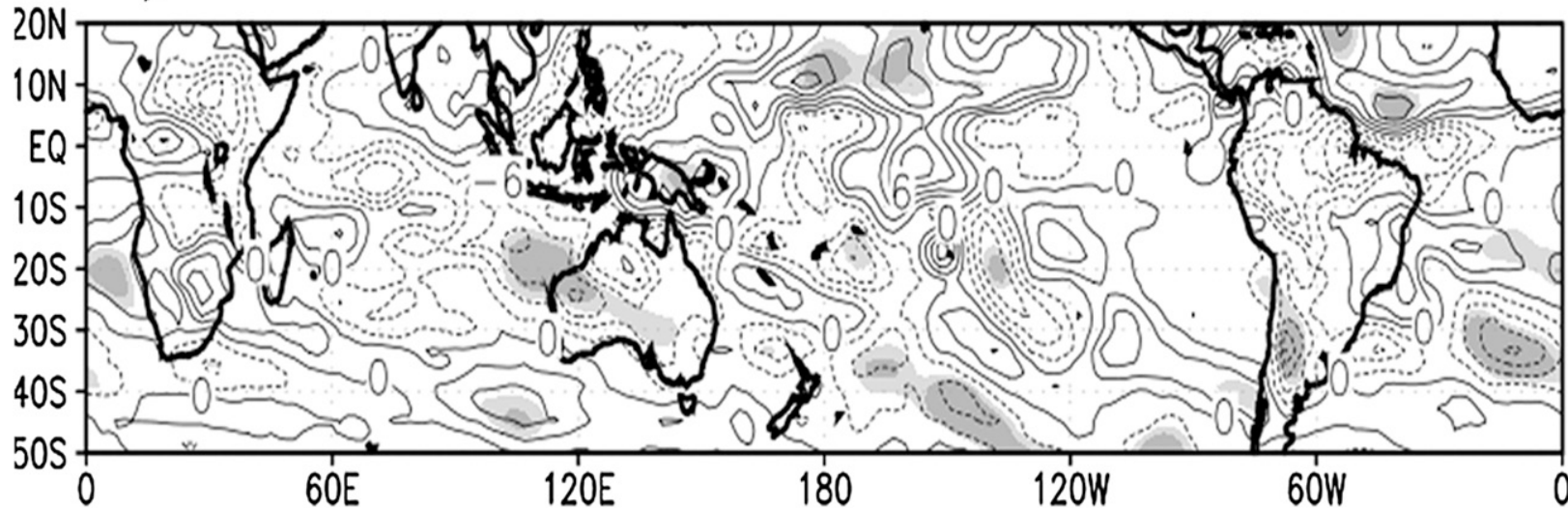

FIG. 8. Anomalous PSI $\left(10 \times \mathrm{e}^{-6} \mathrm{~m}^{2} \mathrm{~s}^{-1}\right)$ eddy and the corresponding horizontal Plumb's stationary wave activity flux (Fs, vector, $\mathrm{m}^{2} \mathrm{~s}^{-2}$ ) at (a) 300 and (b) $850 \mathrm{hPa}$, and (c) 300-hPa OLR wet-minus-dry composite anomalies. Composite anomalies correspond to the period 1959-76. Shaded areas are significant at the $90 \%$ (lighter gray) and $95 \%$ (gray) confidence levels. 
SSTs difference anomalies in 1959-1976

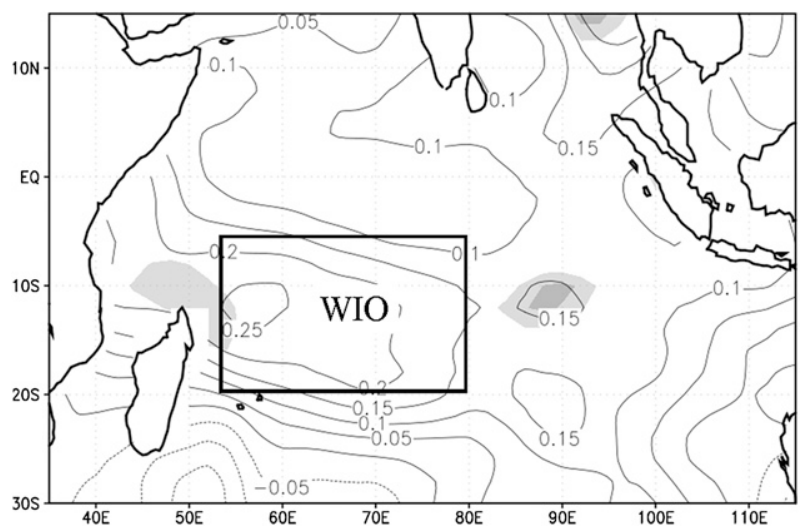

FIG. 9. Wet- minus dry-summer composite-difference anomalies for the SSTs in the tropical Indian Ocean. The WIO: a warmer SST region within $5^{\circ}-20^{\circ} \mathrm{S}, 55^{\circ}-80^{\circ} \mathrm{E}$ in the western south Indian Ocean (Chan et al. 2008).

Indian Ocean could be associated with the stationary wave anomaly in the upper level and subsequent wave activity flux propagation toward Australia (Fig. 8a). In contrast, the negative OLR anomalies at the subtropicalto-midlatitude South Pacific, east of New Zealand, could be associated with anomalous synoptic-scale convection along the storm tracks (Hoskins and Valdes 1990), which can probably be induced by the presence of upper-level quasi-stationary wave anomalies between $180^{\circ}$ and $120^{\circ} \mathrm{W}$.

Thus, QSWs seem to emanate from the south Indian Ocean toward the east and south, crossing over and south of Australia into the midlatitudes. The wave activity convergence could additionally reinforce a second wave propagation from east of New Zealand toward the midlatitude South Pacific and South America. Chan et al. (2008) already pointed out the teleconnections from the southern Indian Ocean affecting precipitation in South America using modeling and observed data. The tropical SST anomalies in the Indian Ocean related to CWA are mostly positive in the western and central sectors, while they are relatively lower in the eastern sector (Fig. 9). In general, positive (negative) SST anomalies off the coast of East Africa in tropical latitudes are mainly related to the Indian Ocean dipole (IOD) event in its positive (negative) phase (Yamagata et al. 2004; Chan et al. 2008).

According to Chan et al. (2008), pure positive IOD events represent a SST warming of about $0.3^{\circ} \mathrm{C}$ that locates roughly south of $5^{\circ} \mathrm{S}$, between $55^{\circ}$ and $80^{\circ} \mathrm{E}$, without ENSO event occurrence. As a result, South American rainfall can be influenced by Rossby wave propagation from the tropical southern Indian Ocean. The mechanism proposed by the authors consists of large streamfunction anomalies over southern Indian Ocean induced by divergence/convergence anomalies. Afterward, the midlatitude waveguide traps propagating Rossby waves along stationary wave paths, crossing the South Pacific and reaching South America.

The SST composite anomalies for CWA summer precipitation (Fig. 9) show positive SST anomalies over $0.20^{\circ} \mathrm{C}$ in the west of southern Indian Ocean. The warmer SST region, at about $5^{\circ}-20^{\circ} \mathrm{S}, 55^{\circ}-80^{\circ} \mathrm{E}$, is located quite similarly to the one used by Chan et al. (2008) to study wave propagation. Hence, this anomalous SST warming in the western south Indian Ocean could possibly trigger the emanation of Rossby waves as observed in Figs. 8a and $8 \mathrm{~b}$. The SST average on that oceanic region in the western south Indian Ocean (at $\left.5^{\circ}-20^{\circ} \mathrm{S}, 55^{\circ}-80^{\circ} \mathrm{E}\right)$ is defined as the western Indian Ocean (WIO) index.

The WIO and the SR indices time series show 30-yr running correlations of almost above the $95 \%$ confidence level throughout the past century until the 1960s, peaking values near 0.5 between 1922 and 1926 (Fig. 10). This means that there exists a stationary relationship during several decades, suggesting a possible low-frequency interaction between the WIO and the CWA rainfall all over the past century. The correlation values decline during the early 1970s to near zero at the end of the decade, evidencing that the WIO and CWA summer rainfalls lose their association thereafter. The loss of association between both regions is consistent with the possibility of teleconnection change due to the climate shift of 1976/77. Therefore, it would be expected to have similar wave propagation throughout the whole past century until the mid-1970s, if quasi-stationary wave propagation from the tropical south Indian Ocean toward South America were effectively the possible supporting mechanism of teleconnection. This hypothesis is further examined in section 6 .

\section{b. ENSO and the QSW propagation prior to $1976 / 77$}

The observed QSW propagation from the India-South Pacific region toward South America may resemble the Pacific-South Atlantic (PSA) 1 and 2 patterns, which are related to both the biennial and the quadrennial oscillations of the ENSO interannual variability (Mo 2000). However, Compagnucci et al. (2002) found the absence of association between the ENSO events and the wet-ordry summer occurrence during the past century. Furthermore, the correlations between the SR index (for CWA summer rainfall) and ENSO indices, such as EN and MEI, yield very low values (below 0.13) for both periods 1959-76 and 1979-2010 as well as in the 19592010 period, being not significantly nonzero even at $90 \%$. The running correlation between both the EN and SR indices (Fig. 11) shows considerable nonstationarity in the relationship, thus confirming that ENSO and the 


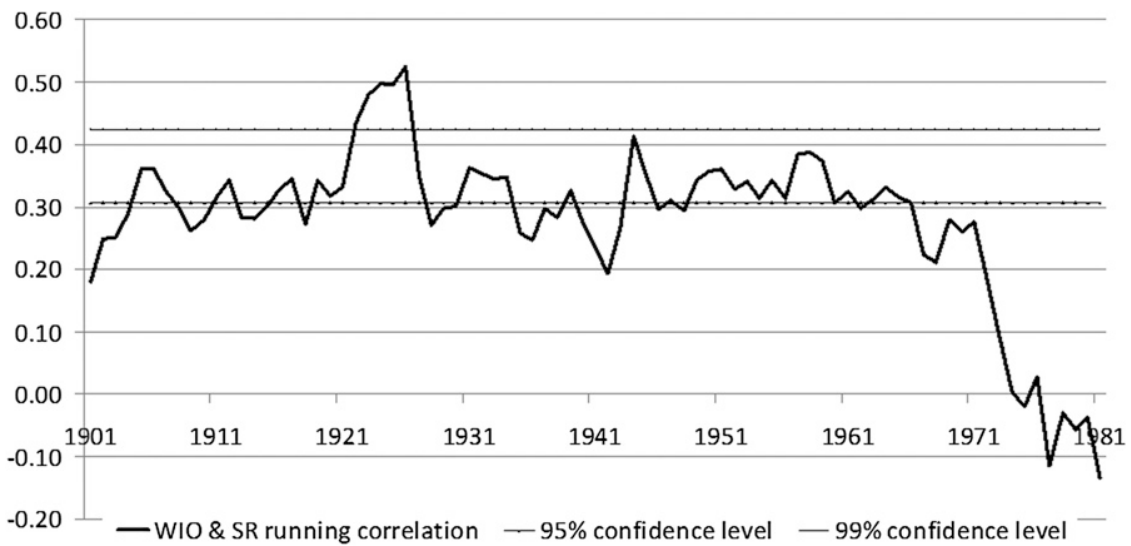

FIG. 10. The 30-yr running correlation between the SST WIO index and the CWA SR index together with the $95 \%$ and $99 \%$ confidence levels according to the one-tail Pearson's coefficient correlation test with $(n-2)$ degree of freedom.

CWA summer rainfall variability are not associated with interannual scales.

\section{c. Teleconnections after 1976/77}

Seasonal quasi-stationary streamfunction perturbations, which propagate zonally throughout the extratropics and are related to CWA summer precipitation, are absent during 1979-2010. Instead, there appear two opposite-sign anomalies around the equator in the central Pacific (Fig. 12a), at about $120^{\circ} \mathrm{W}$, in association with a large area of outflow divergent wind anomalies (Fig. 12b) and with anomalous warming in the central Pacific (Fig. 12c). If the composite years are selected only within the period 1978-98, then PSI composite anomalies are more zonally extended and significantly strengthened (Figs. 13a). Upper-level divergent wind anomalies are also more prominent in the central Pacific, reproducing the Walker cell with descending branches over South America and the Maritime Continent (Fig. 13b). The upper-divergence outflow anomalies correspond with warming in the equatorial central and east Pacific (Fig. 13c). The overall anomalies are clearly associated with ENSO-like conditions predominating after the climate shift of 1976/77. Hemispherically tropospheric circulation symmetric variability about the equator is undoubtedly attributed to the ENSO-like variability (Gill 1980; Rasmusson and Carpenter 1982; Garreaud and Battisti 1999; Seager et al. 2005). The symmetry is caused by anomalous equatorial SSTs at all longitudes, forcing circulation anomalies in the equatorial region and, subsequently, forcing anomalous intensification of the subtropical jets on their equatorward flanks. Anomalous surface fluxes additionally contribute to anomalous cooling of SSTs in the extratropics (Bjerknes 1966, 1969; Lau and Nath 1996), as those observed in Figs. 11c and 12c. This type of tropical forcing of variability is known as the eddy-driven meridional circulations and is another way, in addition to Rossby wave teleconnections, the tropics can influence the extratropical climate (Rasmusson and Carpenter 1982; Seager

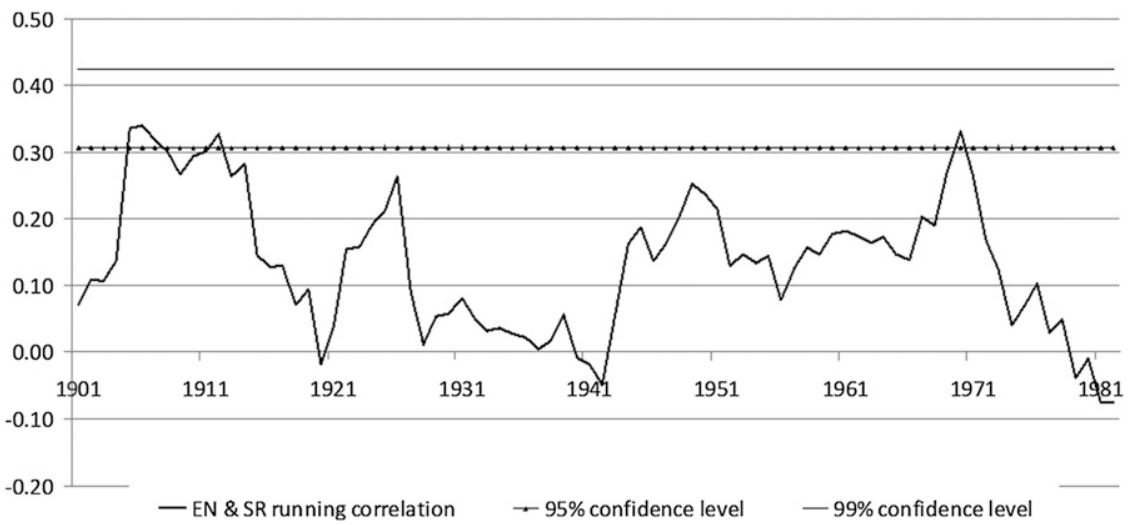

FIG. 11. As in Fig. 10, but between the global EN index and the SR index. 
a) 300hPa PSI eddy

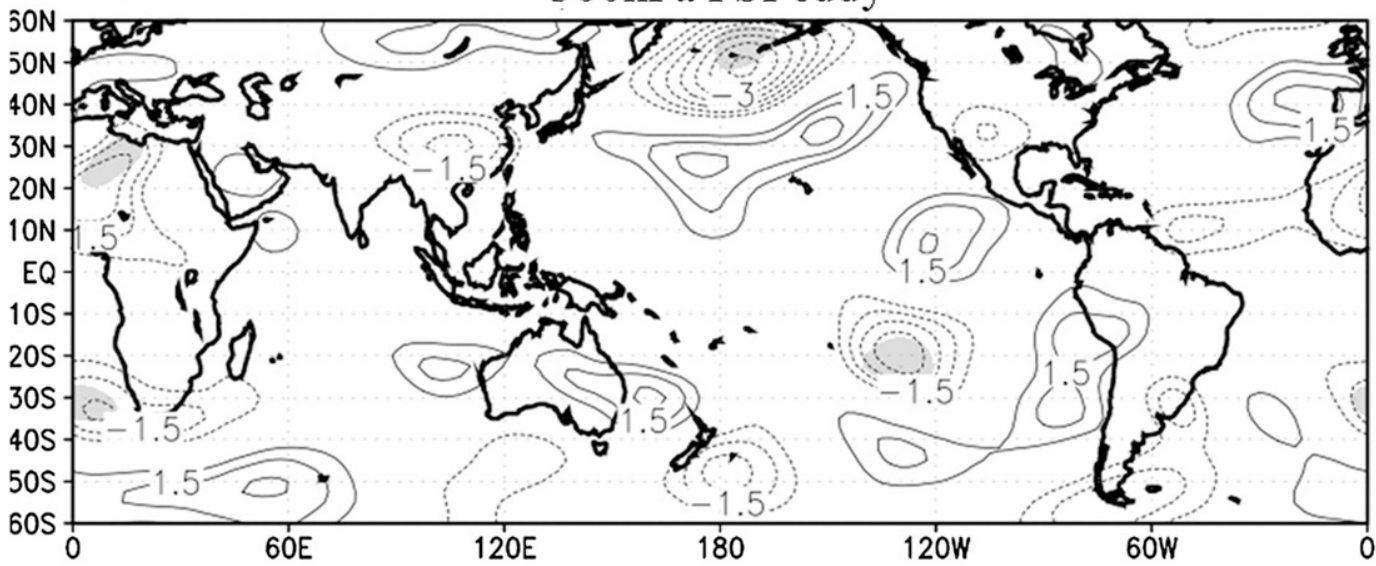

b)

200hPa CHI \& Divergent Wind

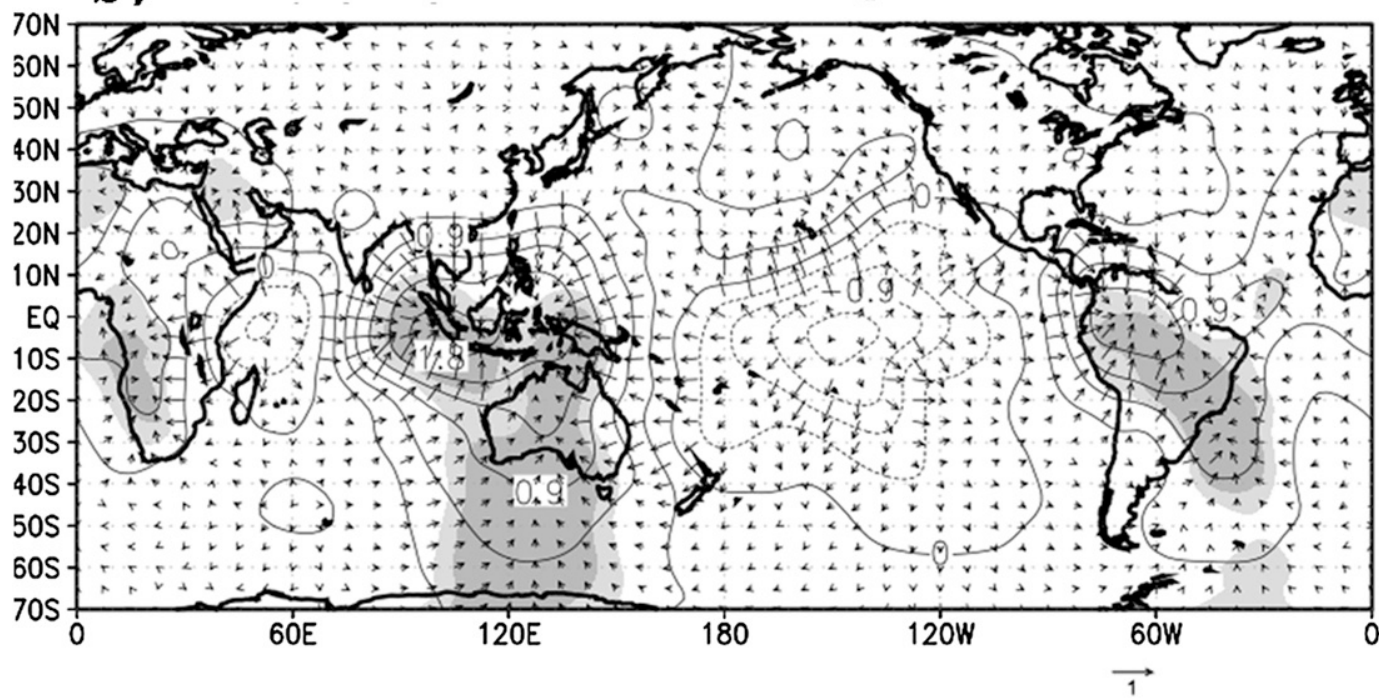

c)

SSTs

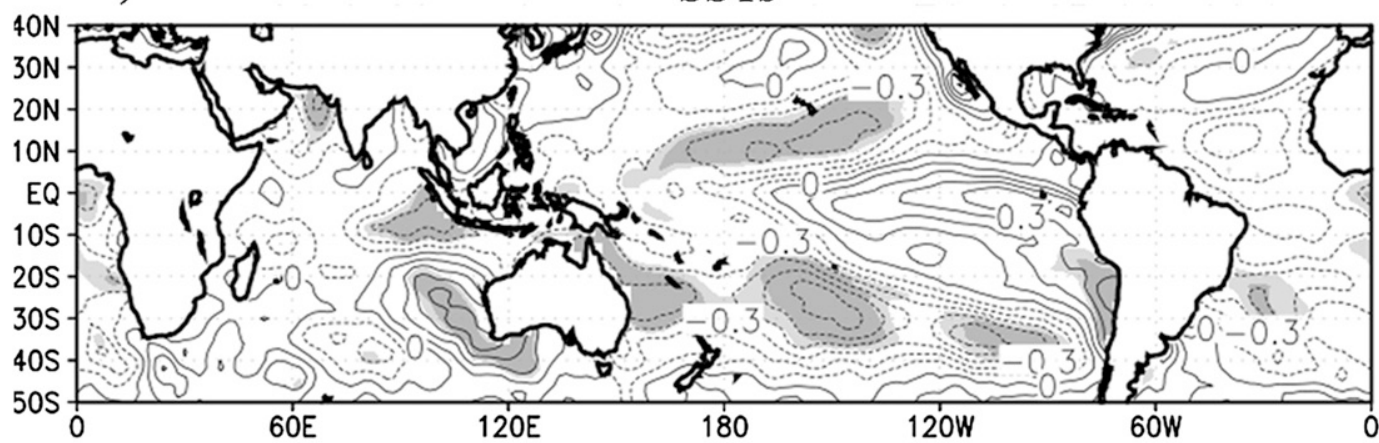

Wet-dry composite difference in the period 1979-2010

FIG. 12. (a) Anomalous PSI $\left(10 \times \mathrm{e}^{-6} \mathrm{~m}^{2} \mathrm{~s}^{-1}\right)$ eddy at $300 \mathrm{hPa}$. Wet- minus dry-composite difference anomalies for (b) 200-hPa CHI $\left(10^{-6} \mathrm{~m}^{2} \mathrm{~s}^{-1}\right)$ and divergent wind vectors $\left(\mathrm{m} \mathrm{s}^{-1}\right)$ and (c) global SSTs. Composites and anomalies correspond to the period 1979-2010. Shaded areas are significant at the $90 \%$ (lighter gray) and $95 \%$ (gray) confidence levels. 
a) $300 \mathrm{hPa}$ PSI eddy

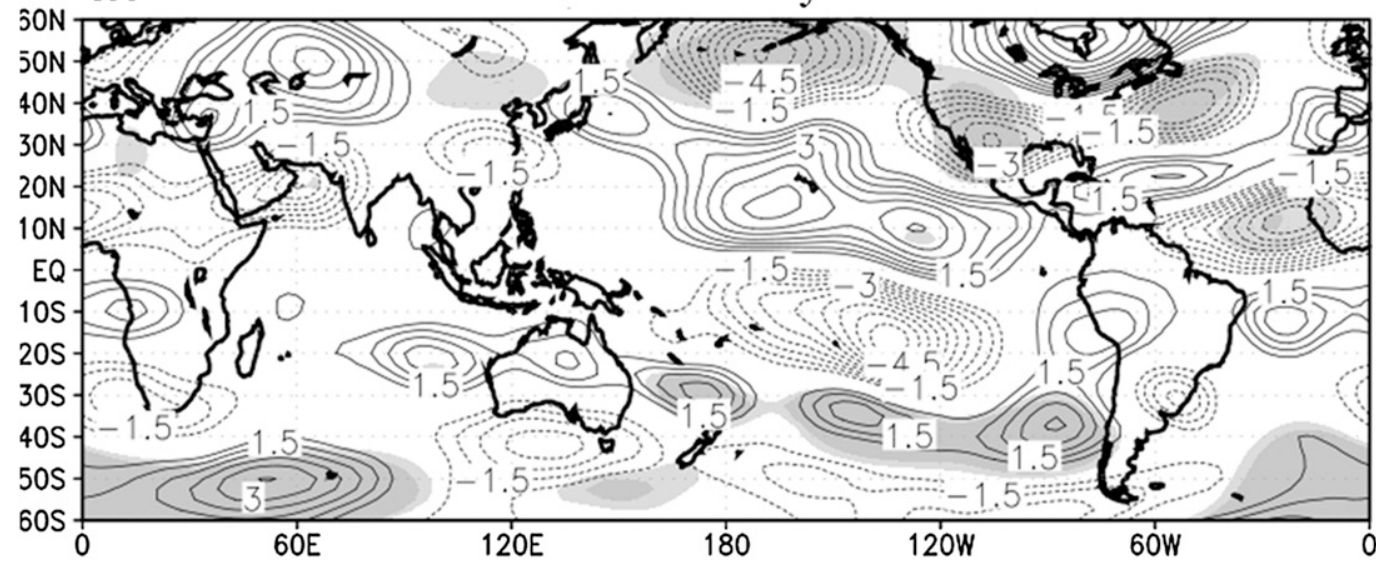

b)

200hPa CHI \& Divergent Wind

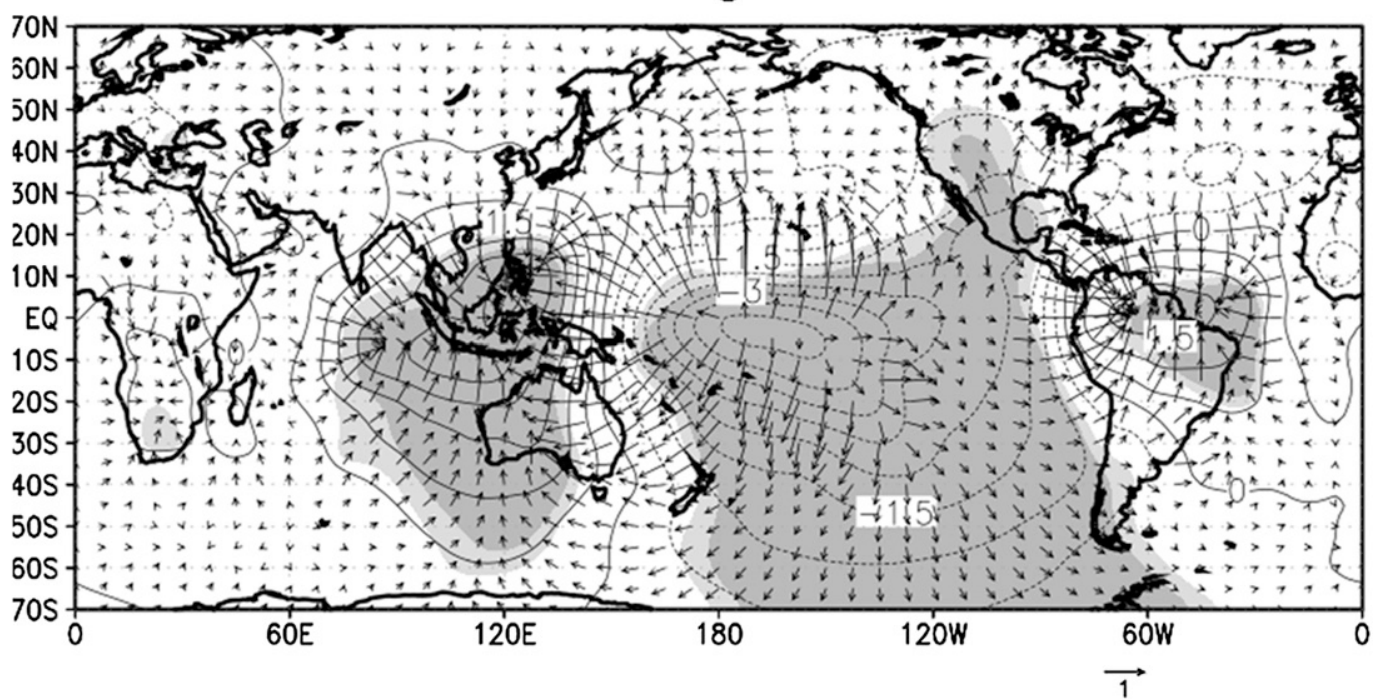

c)

SSTs

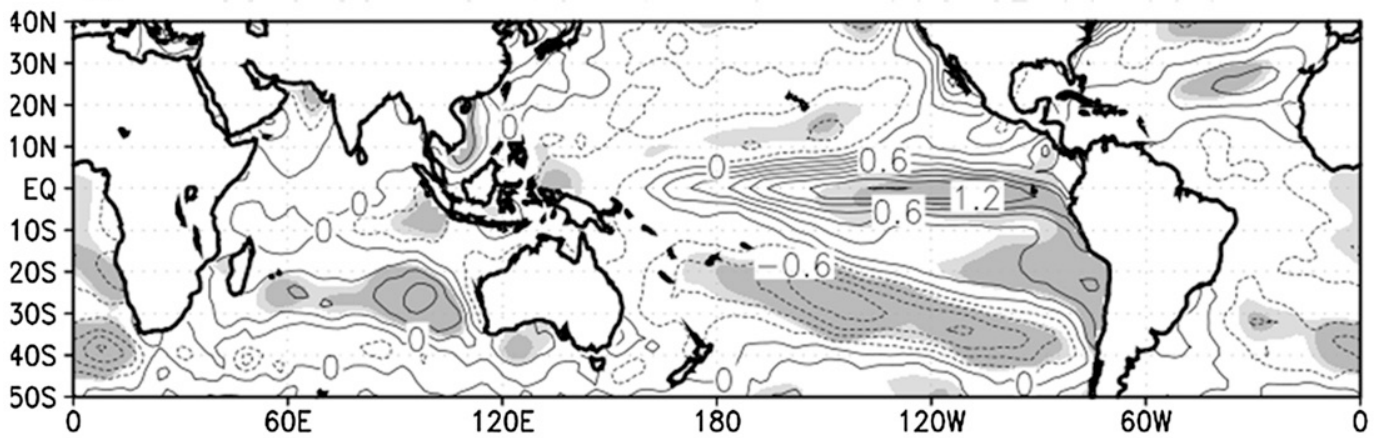

Wet-dry composite difference in the period 1978-1998 
et al. 2005). Therefore, the climate shift of 1976/77 generates a change in the type of teleconnections affecting the tropospheric circulation associated with CWA rainfall variability.

According to Huang et al. (2005), because of a possible reversal in the Pacific low-frequency SST variability, trend reversals might have occurred around 1998 for the South American precipitation series. Actually, CWA rainfall variability undergoes a trend change after the early 2000s (see section 3.1 in Huang et al. 2005). Therefore, the variation in the intensity of the symmetric anomalies over the equatorial central Pacific, associated with the CWA rainfalls (cf. Figs. 12 and 13), furthers suggest that the ENSO-like and CWA precipitation interaction has weakened since, at least, the early 2000s. This fact, together with the generally weak and nonsignificant composite anomalies, shown in section 3.3 of Huang et al. (2005) where wet and dry summers were compounded for the period 1979-2010 (see Fig. 4), suggests that a new configuration of tropospheric circulation anomalies could be arising during the 2000 s, though not statistically discernible yet.

\section{Teleconnections from the beginning of the twentieth century}

Since the lower-frequency variability of CWA rainfalls has only changed by the mid-1970s and it appears to be partly related to wave propagation from the tropical south Indian Ocean and the South Pacific toward South America in association with WIO SST anomalies (see section $4 \mathrm{a}$ ), hence it could be possible to find similar wavelike anomaly propagation during the time before reanalysis data. In this section the analysis of the low-level atmospheric circulation during the twentieth century related to the CWA precipitation is carried out using HadSLP1 data for the period 1900-98 together with the NCEP-NCAR reanalysis SLP data from 1958 onward. The reader is referred to the appendix to see details for choosing the HadSLP1 dataset.

The wet-minus-dry composite difference of HadSLP1 zonal asymmetry and the SST composite anomalies for 1901-58 are shown in Figs. 14a and 14b, respectively. For comparison NCEP-NCAR SLP anomalies for 1959-76 are shown in Fig. 14c. Notice that the QSW propagation associated with CWA rainfall variability prior to 1976/77 (which are observed in Figs. 8a and 8b) appear in the SLP anomaly field, according to Fig. 14c, as a midlatitude wave train from the southern Indian Ocean crossing the South Pacific toward South America. Hence, it is remarkable that such similar QSW-like anomalies can be observed even in the period 1901-58 using HadSLP1 (Fig. 14a). Moreover, the SST anomalies in the WIO region (Fig. 14b), which seems to be a Rossby wave source region for wave propagation from the Indian Ocean (Chan et al. 2008), are significant over a larger area compared with the SST composite anomalies obtained during the NCEP-NCAR reanalysis period (see Fig. 9). Furthermore, the anomalies have a magnitude over $0.3^{\circ} \mathrm{C}$, similar to the ones used by Chan et al. (2008). This result further contributes to the notion that QSWs can effectively propagate from the tropical Indian Ocean as a typical teleconnection characterizing the low-frequency variability of CWA summer precipitation even from the early twentieth century until the mid-1970s.

As described above, the QSW propagation from the southern Indian Ocean and the South Pacific are responsible for stationary tropospheric circulation anomalies over the midlatitude southwestern South Atlantic. The Malvinas/Falkland Islands' (MF) SLP time series is obtained averaging HadSLP1 data on the area between $55^{\circ}$ and $45^{\circ} \mathrm{S}$ and $60^{\circ}$ and $55^{\circ} \mathrm{W}$ near the MF (i.e., in the core of the South American stationary atmospheric circulation anomalies). This time series shows spectral peaks with periods near 4, 8, and 16-22 yr (figures not shown), similar to those obtained for SR index variability (section 3). If the MF SLP time series is smoothed using a 15-term binomial smoothing function and then is compared with the correspondingly smoothed SR time series, it is remarkable their covariability is due to the presence of the common quasi-bidecadal oscillation. This oscillation is dominant in both time series from the 1920s to the late 1970s. Because the HadSLP1 dataset ends in 1998, it is not possible to evaluate whether the low-frequency oscillation of the MF SLP time series extends further in time. In any case, it is clear that the lowfrequency variability in CWA summer rainfalls appears to be driven by anomalous stationary tropospheric circulation over the midlatitude southwestern South Atlantic until the mid-1970s.

According to Compagnucci et al. (2002), the quasibidecadal oscillation is a common feature shared with the South African SRR precipitation, through which both the CWA and SRR precipitation time series were in phase related to the period prior to the mid-1970s. Afterward, the in-phase relationship was lost because of spectral variations on the CWA summer precipitation variability (Compagnucci et al. 2002), which have been shown in section 3. Therefore, a hypothesis that needs to be further examined is that the QSW propagation from the South Pacific and crossing South America toward the South Atlantic and southern Africa (see Figs. 8a,b and 14a) could be responsible for the former in-phase relationship established between both the CWA and SSR precipitation time series in the time before the 


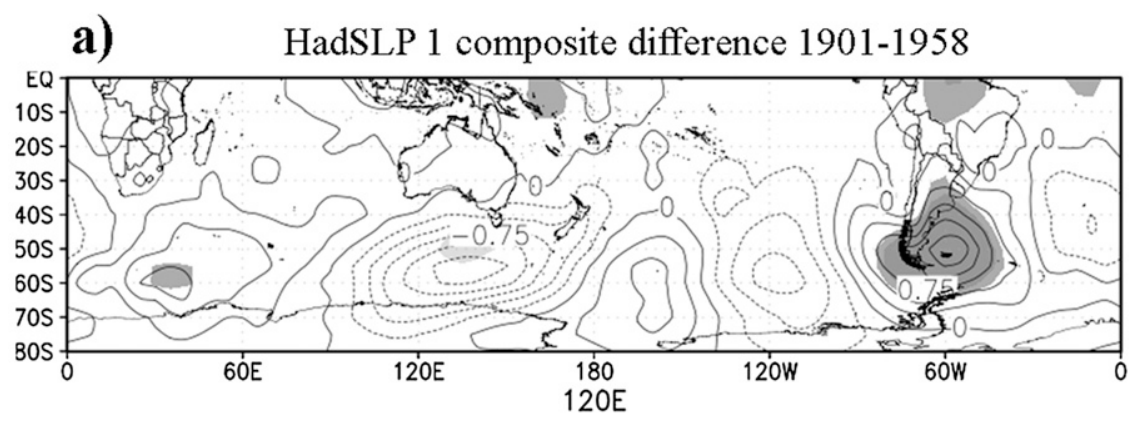

b)

SSTs composite difference 1901-1958

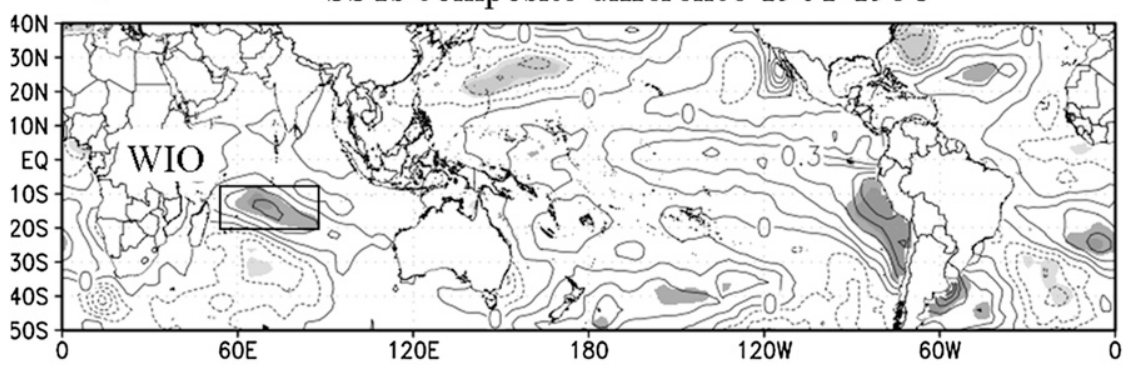

c)

SLP composite difference 1959-1976

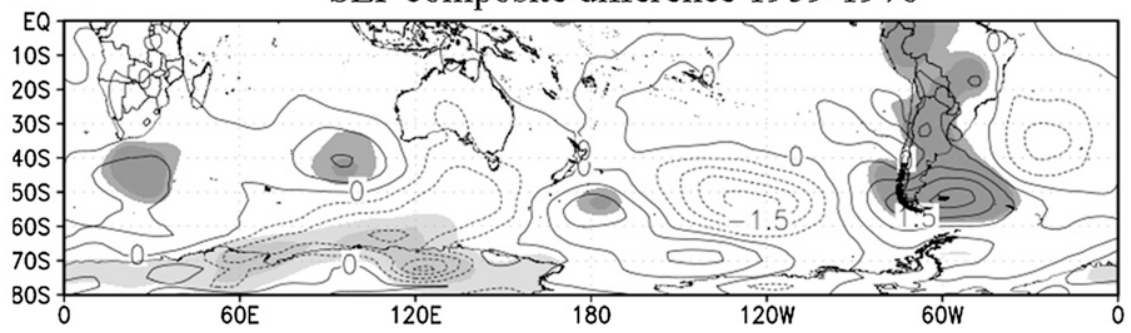

FIG. 14. Wet-minus-dry composite difference for the (a) HadSLP1 data, (b) SSTs in the summer period 1901-58, and (c) SLP data from the NCEP-NCAR reanalysis in the period 1959-76. Shaded areas indicate significant anomalies at the $90 \%$ (lighter gray) and $95 \%$ (gray) confidence levels.

1970s. The SRR precipitation has undergone no spectral changes throughout the twentieth century (Triegaardt and Landman 1995; Lizcano and Todd 2005), which could mean that the teleconnection change produced by the climate shift locally affected CWA rainfalls solely.

Understanding the nature of this quasi-bidecadal oscillation is beyond the scope of the current work. However, it could be linked to complex SST-atmosphere coupling interactions, since the Indian Ocean, and specifically the WIO SST time series, show decadal variability (9-35 yr) closely related to the Pacific-ENSO-like decadal variability (Tozuka et al. 2007).

\section{Conclusions}

In this work the CWA interannual-to-multidecadal summer precipitation variability has been analyzed through spectral techniques in the period 1900-2010 together with tropospheric circulation variations related to precipitation. Significant quasi cycles are present in the CWA summer precipitation in periods of about $2,4-5,6-8$, and 16-22 yr. These modes of variability also vary throughout time. It is also apparent a 45-yr quasi oscillation dominates between the 1930s and the 1970s. The quasi-bidecadal oscillation with periods of about $16-22 \mathrm{yr}$ is prominent from the early 1910s until the 1970s, producing sensible alternating periods of wet and dry summers roughly every 9 yr. Afterward, the quasi-bidecadal cycle decays, leading to a wet spell longer than $30 \mathrm{yr}$. The wet spell starts in the summer of 1973 as part of the positive phase of the quasibidecadal oscillation and extends until the early 2000s. Since then, there is a trend change whose statistical significance is not yet possible to estimate; however, it puts into doubt the permanence of the wet spell. Whether its 
moderation during the last decade is about to last or not is a completely open question. As a consequence, there is a net increment in the number of wet summers, resulting in a precipitation increase of about $24 \%$ from 1973 onward.

Based on AC08's results, regarding the climate shift of 1976/77 and its effects on the summer tropospheric circulation and precipitation budget over southern South America, the seasonal circulation composite anomalies associated with wet and dry summers in CWA have been studied for the subperiods before and after 1976/77 using the NCEP-NCAR reanalysis data for the period 19592010 and reconstructed SLP data (HadSLP 1) for the period 1901-58.

From the early twentieth century to the mid-1970s, the summer precipitation is associated with tropical-tomidlatitude barotropic QSW propagation from the southern Indian Ocean and the South Pacific. Continental tropospheric circulation anomalies imposed by the teleconnection over southern South America generate moisture and vertical motion anomalies at mid-tosubtropical latitudes east of the Andes, where the CWA region is located. This QSW propagation could be related to anomalous deep convection induced, partly, by tropical anomalous SSTs in the western south Indian Ocean (WIO) region (centered at about $12.5^{\circ} \mathrm{S}, 65^{\circ} \mathrm{E}$ ). Other convection anomalies over the midlatitude South Pacific, to the east of New Zealand, could be due to circulation anomalies induced by the presence of stationary tropospheric circulation anomalies modulating the storm-track activity there, thus additionally emanating QSW energy eastward.

The quasi-bidecadal oscillation is likewise observed in the tropospheric circulation over the southwestern South Atlantic, near the Malvinas/Falkland Islands, associated with QSW propagation. Thus, both the MF SLP and CWA summer precipitation time series show lowfrequency covariability during the twentieth century until at least the late 1970s. Noticeably, this quasi-bidecadal oscillation is also present in the South African SRR precipitation time series (Lizcano and Todd 2005) and covaried together with the CWA rainfall time series until the mid-1970s (Compagnucci et al. 2002). Therefore, the further eastward QSW propagation from the South Pacific and crossing the South Atlantic toward southern South Africa could be responsible for the former in-phase relationship between both remote regions. The hypothesis should be further analyzed.

After the climate shift in 1976/77, the CWA summer precipitation variability is related to zonally extended opposite-sign anomalies around the equator, which are undoubtedly linked to ENSO-like warmer conditions predominating after 1976/77 in the equatorial-central Pacific (Seager et al. 2005). Regionally, the circulation anomalies generate moisture anomalies to the east of the Andes range, from CWA toward the northeast. This fact further emphasizes that air masses are advected from lower latitudes. In fact, wet (dry) summers are associated with inflation (deflation) of the SAA western flank in the surroundings of South America after 1976/77.

Hemispherically symmetric anomalies around the equator are further emphasized if composites are calculated from 1978 to 1998. It means that approximately from the 2000s onward, the circulation anomalies associated with precipitation in CWA could be changing toward a different configuration. Huang et al. (2005) suggested that trend reversals might have occurred after 1998 in South American precipitation series due to a possible reversal in the El Niño-like SST variability. This is consistent with the fact that the CWA precipitation variability is undergoing a negative trend change since the early 2000s that has not yet consolidated.

Hence, results show that the 1976/77 climate shift effect on the CWA summer precipitation is through changes in hemispherical atmospheric teleconnections. Consequently, there appears to be changes in stationary tropospheric circulation anomalies over southern South America, from midlatitudes toward lower latitudes, bringing wetter air masses from the tropical South Atlantic during the warm season. Out of that the CWA summer precipitation variability is unrelated to the ENSO events at interannual scales. Further analysis will explore the low-frequency variability in tropical SSTs over the Indian Ocean, especially over the WIO region, and the $\mathrm{SH}$ midlatitude tropospheric circulation to shed more light on the nature of the quasi-bidecadal oscillation present in hemispherical teleconnections that are linked to the precipitation variability in both CWA and SRR remote regions.

Acknowledgments. This research was supported by CONICET's PIPs 112-2009-0100439, 5006 (2008-2010), and 114-201001-00250 (2011-2013); ANCyT's PICTs 2007-00438 and 2007-01888 (ICES/IDAC); and UBA's UBACYT X-016. Expressed gratitude is given to the Carmelite Order for all their help.

\section{APPENDIX}

\section{Comparison of the Hadley Centre Sea Level Pressure Datasets}

The Hadley Centre offers two datasets for globally complete monthly gridded mean SLP: HadSLP1 (18711998) and HadSLP2 (1850-present). Both datasets were 
a) NCEP/NCAR SLP

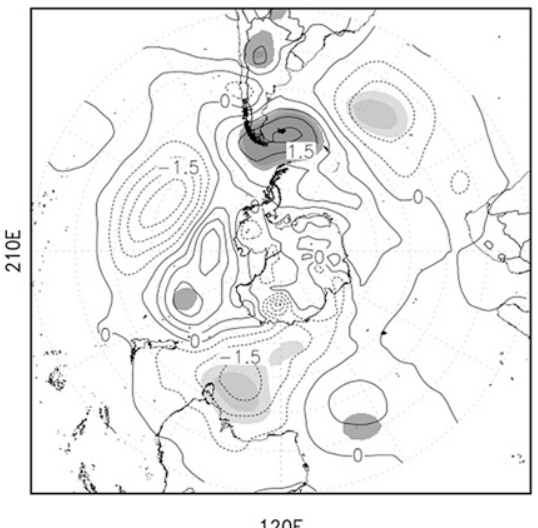

$120 \mathrm{E}$ b) HadSLP1

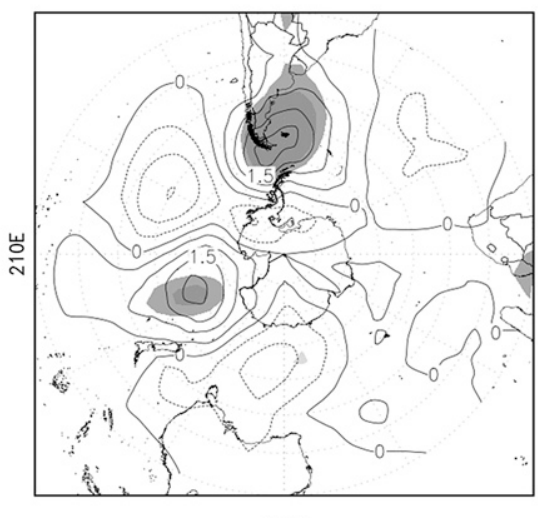

$120 \mathrm{E}$ c) HadSLP2

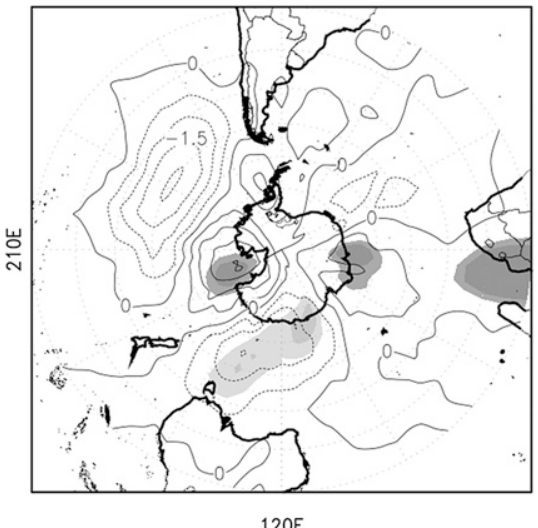

Summer period 1959-1976

FIG. A1. SLP wet- minus dry-composite difference anomalies obtained from (a) NCEP-NCAR, (b) HadSLP1, and (c) HadSLP2 in the summer period 1959-76 related to CWA summer rainfalls. Shaded areas indicate significant anomalies at the $90 \%$ (lighter gray) and $95 \%$ (gray) confidence levels.

compared with the NCEP-NCAR SLP data by means of wet-minus-dry summer composite anomalies related to CWA summer precipitation during the summer period 1959-76 (for further details see main text). The SLP composite difference anomalies are shown in Fig. A1 for NCEP-NCAR (Fig. A1a, using polar stereographic projection comparable to Fig. 14c), HadSLP1 (Fig. A1b), and HadSLP2 (Fig. A1c) datasets.

The overall SLP anomalies show a midlatitude wavelike pattern extending from the southern Indian Ocean and the South Pacific toward the South Atlantic (Fig. A1a). HadSLP1 reconstructed anomalies (Fig. A1b) are quite similar in location and intensity to those from NCEPNCAR, especially the positive anomaly center that is located approximately over the Malvinas/Falkland Islands. This SLP anomaly center is directly related to CWA rainfall variability during the period 1959-76 (see section 4). Surprisingly, HadSLP2 anomalies do not reproduce well the wave-like SLP anomaly pattern, including the positive SLP anomaly center over the Malvinas/Falkland Islands. Furthermore, the summer SLP time series at the Stanley meteorological station (available in the period 1923-83 without interruption), located in the Malvinas/Falkland Islands, shows a stronger correlation with the HadSLP1 time series (0.93) than with the corresponding HadSLP2 time series (0.73), both obtained using the nearest gridded points. The three SLP time series are shown in Fig. A2 for comparison.

In addition, if the summer SLP is averaged in the latitude band $40^{\circ}-70^{\circ} \mathrm{S}$ for every dataset, then the resulting averaged SLP time series show the strongest correlation between NCEP and NCAR and HadSLP1, with a correlation of 0.73 during 1959-98. In the same period, the correlation between the NCEPNCAR and HadSLP2 averaged time series is 0.33 . The HadSLP2 also overestimates both the NCEP-NCAR SLP and HadSLP1 in about $1 \mathrm{hPa}$ in average over that latitude band (figures not shown). Both the mean SLP overestimation and low correlation values shown by HadSLP2 over midlatitude SH have already been pointed out by Allan and Ansell (2006). Therefore, historical SLP anomalies provided by HadSLP1 are preferred to study the low-level circulation associated with CWA rainfall variability in the period 1901-58.

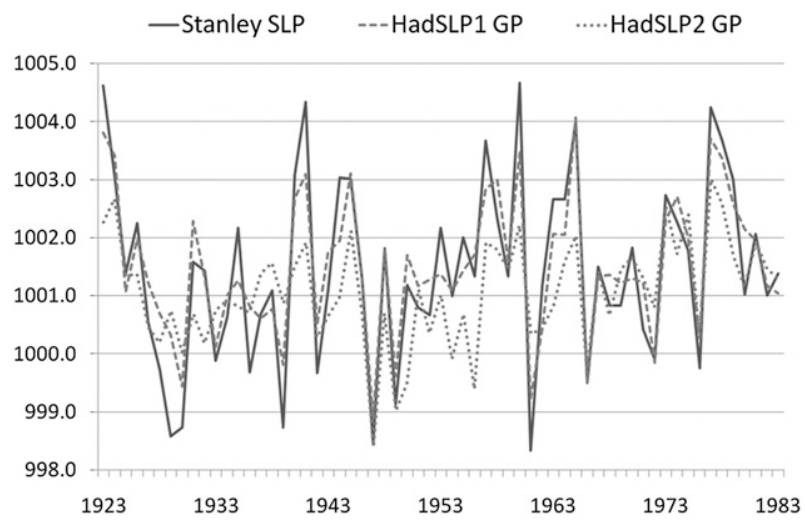

FIG. A2. Observational SLP time series from station data at Stanley (at $51.70^{\circ} \mathrm{S}, 57.85^{\circ} \mathrm{W}$; solid line) and the corresponding HadSLP1 (dashed line) and HadSLP 2 (dotted line) time series at the nearest gridded point (GP). 


\section{REFERENCES}

Agosta, E. A., and R. H. Compagnucci, 2006: Atmospheric conditions during wet and dry summer extremes in central-west Argentina. Proc. Eighth Int. Conf. on Southern Hemisphere Meteorology and Oceanography, Foz do Iguaçu, Paraná State, Brazil, INPE, 1439-1452. [Available online at http://mtcm15.sid.inpe.br/col/cptec.inpe.br/adm_conf/2005/10.28.02.57/ doc/1439-1452.pdf.]

— and - 2008: The 1976/77 austral summer climate transition effects on the atmospheric circulation and climate in southern South America. J. Climate, 21, 4365-4383.

— , and M. Cavagnaro, 2010: Variaciones interanuales de la precipitación de verano y el rendimiento del cultivo de la vid en Mendoza. Geoacta, 35 (2), 1-11.

—, R. H. Compagnucci, and M. W. Vargas 1999: Cambios en el régimen interannual de la precipitación en la región CentroOste de Argentina. Meteorologica, 24, 63-84.

Allan, R., and T. Ansell, 2006: A new globally complete monthly historical gridded mean sea level pressure dataset (HadSLP2): 1850-2004. J. Climate, 19, 5816-5834.

Barreiro, M., 2010: Influence of ENSO and the South Atlantic Ocean on climate predictability over southeastern South America. Climate Dyn., 35, 1493-1508, doi:10.1007/s00382-009-0666-9.

Barros, V., M. Castañeda, and M. Doyle, 1996: Recent precipitation trends in southern South America to the east of the Andes: An indication of a mode of climatic variability. Greenhouse Gas Emission under Developing Countries Point of View, L. P. Rosa and M. A. Santos, Eds., COPPE, 41-67.

- M. E. Casteñeda, and M. Doyle, 2000: Recent precipitation trends in southern South America east of the Andes: An indication of climatic variability. Southern Hemisphere Paleoand Neoclimates: Key Sites, Methods, Data and Models, P. P. Smolka and W. Volkheimer, Eds., Springer, 381 pp.

—, M. E. Doyle, and I. A. Camillioni, 2008: Precipitation trends in southeastern South America: Relationship with ENSO phases and with low-level circulation. Theor. Appl. Climatol., 93, 19-33, doi:10.1007/s00704-007-0329-x.

Bjerknes, J., 1966: A possible response of the atmospheric Hadley circulation to equatorial anomalies of ocean temperature. Tellus, 18, 820-829.

- 1969: Atmospheric teleconnection from the equatorial $\mathrm{Pa}-$ cific. Mon. Wea. Rev., 97, 163-172.

Chan, S. C., S. K. Behera, and T. Yamagata, 2008: Indian Ocean dipole influence on South American rainfall. Geophys. Res. Lett., 35, L14S12, doi:10.1029/2008GL034204.

Compagnucci, R. H., E. A. Agosta, and M. W. Vargas, 2002: Climatic change and quasi-oscillations in central-west Argentina summer precipitation: Main features and coherent behaviour with southern African region. Climate Dyn., 18, 421-435.

Dettinger, M. D., D. S. Battisti, R. D. Garreaud, G. J. McCabe, and C. M. Bitz, 2001: Interhemispheric effects of interannual and decadal ENSO-like climate variations on the Americas. Interhemispheric Climate Linkages: Present and Past Climates in the Americas and their Societal Effects, V. Markgraf, Ed., Academic Press, 1-16.

Ebbesmeyer, C. C., D. R. Cayan, D. R. McLain, F. H. Nichols, D. H. Peterson, and T. Redmond, 1991: 1976 step in the Pacific climate: Forty environmental changes between 1968-1975 and 1977-1984. Proceedings of the Seventh Annual Pacific Climate (PACLIM) Workshop, J. L. Betancourt and V. L. Tharp, Eds., California Department of Water Resources, Interagency Ecological Studies Program Tech. Rep. 26, 115-126.
Garreaud, R. D., and D. S. Battisti, 1999: Interannual (ENSO) and interdecadal (ENSO-like) variability in the Southern Hemisphere tropospheric circulation. J. Climate., 12, 2113-2123.

Gill, A. E., 1980: Some simple solutions for heat-induced tropical circulation. Quart. J. Roy. Meteor. Soc., 106, 447-462.

Hoffmann, J. A. J., 1992: The continental atmospheric pressure and precipitation regime of South America (in German). Erdkunde, 46, 40-51.

Hoskins, B. J., and P. J. Valdes, 1990: On the existence of stormtracks. J. Atmos. Sci., 47, 1854-1864.

Huang, H.-P., R. Seager, and Y. Kushnir, 2005: The 1976/77 transition in precipitation over the Americas and the influence of tropical sea surface temperature. Climate Dyn., 24, 721-740.

Karoly, D. J., R. A. Plumb, and M. Ting, 1989: Examples of the horizontal propagation of quasi-stationary waves. J. Atmos. Sci., 46, 2802-2811.

Kistler, R., and Coauthors, 2001: The NCEP-NCAR 50-Year Reanalysis: Monthly means CD-ROM and documentation. Bull. Amer. Meteor. Soc., 82, 247-267.

Lau, N.-C., and M. J. Nath, 1996: The role of the "atmospheric bridge" in linking tropical Pacific ENSO events to extratropical SST anomalies. J. Climate, 9, 2036-2057.

Lizcano, G., and M. C. Todd, 2005: Non-ENSO control on southern Africa precipitation variability. Philos. Trans. Roy. Soc. London, A363, 61-62.

Lozowski, E. P., R. B. Charlton, C. D. Nguyen, and J. D. Wilson, 1989: The use of cumulative monthly mean temperature anomalies in the analysis of local interannual climate variability. J. Climate, 2, 1059-1068.

Mantua, N. J., S. R. Hare, Y. Zhang, J. M. Wallace, and R. C. Francis, 1997: A Pacific interdecadal climate oscillation with impacts on salmon production. Bull. Amer. Meteor. Soc., 78, 1069-1079.

Mason, S. J., 1996: Rainfall trends over the Lowveld of South Africa. Climatic Change, 32, 35-54.

Mo, K. C., 2000: Relationships between low-frequency variability in the Southern Hemisphere and sea surface temperature anomalies. J. Climate, 13, 3599-3610.

Moser, B. K., and G. R. Stevens, 1992: Homogeneity of variance in the two-sample means test. Amer. Stat., 46, 19-21.

Namias, J., 1978: Multiple causes of the North American abnormal winter 1976-77. Mon. Wea. Rev., 106, 279-295.

Nogués-Paegle, J., and Coauthors 2002: Progress in pan American CLIVAR research: Understanding the South American monsoon. Meteorologica, 27, 3-30.

Pavia, E. G., and F. Graef, 2002: The recent rainfall climatology of the Mediterranean Californias. J. Climate, 15, 2697-2701.

Piovano, E. L., D. Ariztegui, S. M. Bernasconi, and J. A. McKenzie, 2004: Stable isotopic record of hydrological changes in subtropical Laguna Mar Chiquita (Argentina) over last 230 years. Holocene, 14, 525-535.

Plumb, R. A., 1985: On the three-dimensional propagation of stationary waves. J. Atmos. Sci., 42, 217-229.

Rasmusson, E. M., and T. H. Carpenter, 1982: Variations in tropical sea surface temperature and surface winds fields associated with the Southern Oscillation/El Niño. Mon. Wea. Rev., 110, 354-384

Renom, M., M. Rusticucci, and M. Barreiro, 2011: Multidecadal changes in the relationship between extreme temperature events in Uruguay and the general atmospheric circulation. Climate Dyn., 37, 2471-2480, doi:10.1007/s00382-010-0986-9.

Robertson, A., and C. Mechoso, 1998: Interannual and decadal cycles in river flows of southeastern South America. J. Climate, 11, 2570-2581. 
Rusticucci, M., and O. Penalba, 2000: Interdecadal changes in the precipitation seasonal cycle over southern South America and their relationship with surface temperature. Climate Res., 16, 1-15.

Sardeshmukh, P. D., and B. J. Hoskins, 1988: The generation of global rotational flow by steady idealized tropical divergence. J. Atmos. Sci., 45, 1228-1251.

Schwerdtfeger, W., 1976: The atmospheric circulation over Central and South America. Climates of Central and South America, W. Schwerdtfeger, Ed., World Survey of Climatology Series, Vol. 12, Elsevier, 2-12.

Seager, R., N. Harnik, W. A. Robinson, Y. Kushnir, M. Ting, H. P. Huang, and J. Velez, 2005: Mechanisms of ENSO-forcing of hemispherically symmetric precipitation variability. Quart. J. Roy. Meteor. Soc., 131, 1501-1527.

Solomon, S., D. Qin, M. Manning, M. Marquis, K. Averyt, M. M. B. Tignor, H. L. Miller Jr., and Z. Chen, Eds., 2007: Climate Change 2007: The Physical Science Basis. Cambridge University Press, $996 \mathrm{pp}$.

Swarztrauber, P., and R. Sweet, 1975: Efficient FORTRAN subprograms for the solution of elliptic partial differential equations. NCAR Tech. Note NCAR-TN/IA-109, 159 pp.
Torrence, C., and G. P. Compo, 1998: A practical guide to wavelet analysis. Bull. Amer. Meteor. Soc., 79, 61-78.

Tozuka, T., J.-J. Lou, S. Masson, and T. Yamagata, 2007: Decadal modulations of the Indian Ocean dipole in the SINTEX-F1 coupled GCM. J. Climate, 20, 2881-2894.

Triegaardt, D. O., and W. A. Landman, 1995: The influence of atmospheric long-waves on summer rainfall in the Transvaal, Orange Free State and Natal. South African Weather Bureau Tech. Paper 26, 75 pp.

Tyson, P. D., 1986: Climatic Change and Variability in Southern Africa. Oxford University Press, $220 \mathrm{pp}$.

— - T. G. J. Dyer, and M. N. Mametse, 1975: Secular changes in South Africa rainfall: 1880 to 1972. Quart. J. Roy. Meteor. Soc., 101, 817-833.

Yamagata, T., S. K. Behera, J.-J. Luo, S. Masson, M. R. Jury, and S. A. Rao, 2004: Coupled ocean-atmosphere variability in the tropical Indian Ocean. Earth Climate: The Ocean-Atmosphere Interaction, Geophys. Monogr.,Vol. 47, Amer. Geophys. Union, 189-212.

Yamamoto, R., Y. Iwashima, and T. Sanga, 1986: An analysis of climatic jump. J. Meteor. Soc. Japan, 64, 273-280. 